\title{
Paisajes artísticos velados. La cabecera románica de la catedral de Sigüenza y la posible difusión del modelo
}

\author{
Veiled artistic landscapes. The Romanesque sanctuary of \\ the Sigüenza catedral and the likely spreading of its model
}

María Concepción COSMEN ALONSO

Instituto de Estudios Medievales. Universidad de León

Recibido: 15-III-2016

Aceptado: 27-IV-2016

Resumen: Los trabajos realizados en la catedral de Sigüenza en el siglo XVI eliminaron y ocultaron en parte sus ábsides románicos. La restauración del retablo llevada a cabo en los años 2009-2011 facilitó el acceso al muro de cierre del ábside principal y dejó a la vista parte del diseño original, lo que ha permitido emparentarlo con obras del suroeste francés, de donde procedía el patrocinador y primer obispo de esta sede.

Palabras clave: Arte románico, Arquitectura, Catedral, Ábside, Obispo, Patrocinio.

ABSTRACT: The works carried out in the Sigüenza cathedral in the 16th century partially removed and hid its romanesque apses. The restoration of the altarpiece done in 2009-2011 made possible the access to the enclosing wall of the main apse and left open part of its original design, which has allowed the comparison with other works in the French South-West, where the mentor and first bishop on this diocese was coming from.

Keywords: Romanesque art, Architecture, Cathedral, Apse, Bishop, Patronage.

La finalidad de este trabajo es dar a conocer el trazado original del presbiterio de la iglesia mayor seguntina, obra que posiblemente se proyectó en la primera mitad del siglo XII.

Las circunstancias que han motivado este nuevo estudio se produjeron al revisar el centro catedralicio citado, pues formaba parte del Proyecto de Investigación que estábamos llevando a cabo en relación con el papel del clero dentro del patrocinio regio, leonés y castellano, desde 1050 a $1200^{1}$.

En este contexto, el interés que manifestó el equipo investigador ante el canónigo -encargado de patrimonio- del cabildo de Si-

\footnotetext{
${ }^{1}$ El presente artículo se ha elaborado en el marco del proyecto El patronazgo artístico regio en el territorio castellano-leonés. El papel del clero (1055-1200) -HAR 2010-19480financiado por el Ministerio de Ciencia e Innovación.
} 


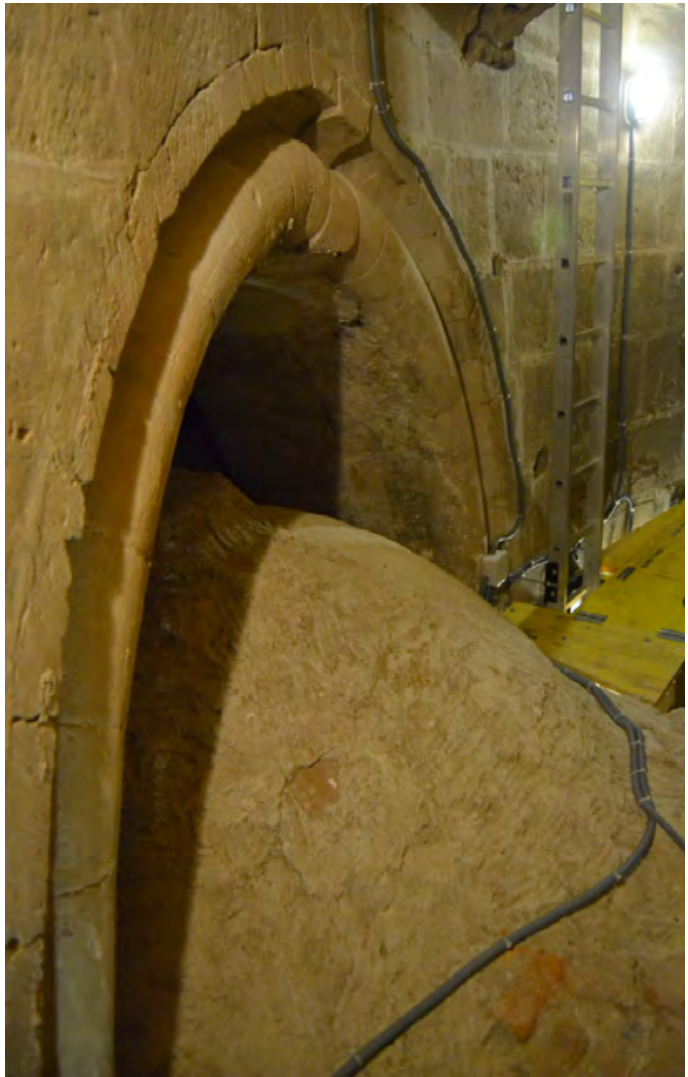

- Fig. 1. Catedral de Sigüenza. Muro interno del ábside principal. Arco de enmarque de la absidiola central y trasdós de la bóveda del camarín. Foto de la autora.

güenza, por recorrer todos los espacios que pudieran aportar alguna novedad, tras las campañas de restauración y excavación de los últimos años, lo llevó a conducirnos, por la zona posterior del retablo mayor, a los restos del muro de la antigua cabecera ${ }^{2}$. Allí, a unos cinco metros de altura, se podía percibir el arco de enmarque superior y la concavidad de la absidiola central, que se abría al semicírculo del testero (Fig. 1). Por otra parte, en sucesivas visitas, se advirtieron, a cierta distancia y a ambos lados de dicha estructura, dos arcos tapiados que parecen dar paso a otros dos ámbitos de trazado semejante (Fig. 2). Por lo tanto, la revisión de lo que fue la cabecera del templo debía llevarse a cabo.

\footnotetext{
${ }^{2}$ Queremos agradecer a don Julián García, canónigo encargado del Patrimonio de la Iglesia de Sigüenza, su ayuda inestimable, así como al doctor Peces Rata, canónigo archivero de la misma sede, su generosidad y disponibilidad.
}

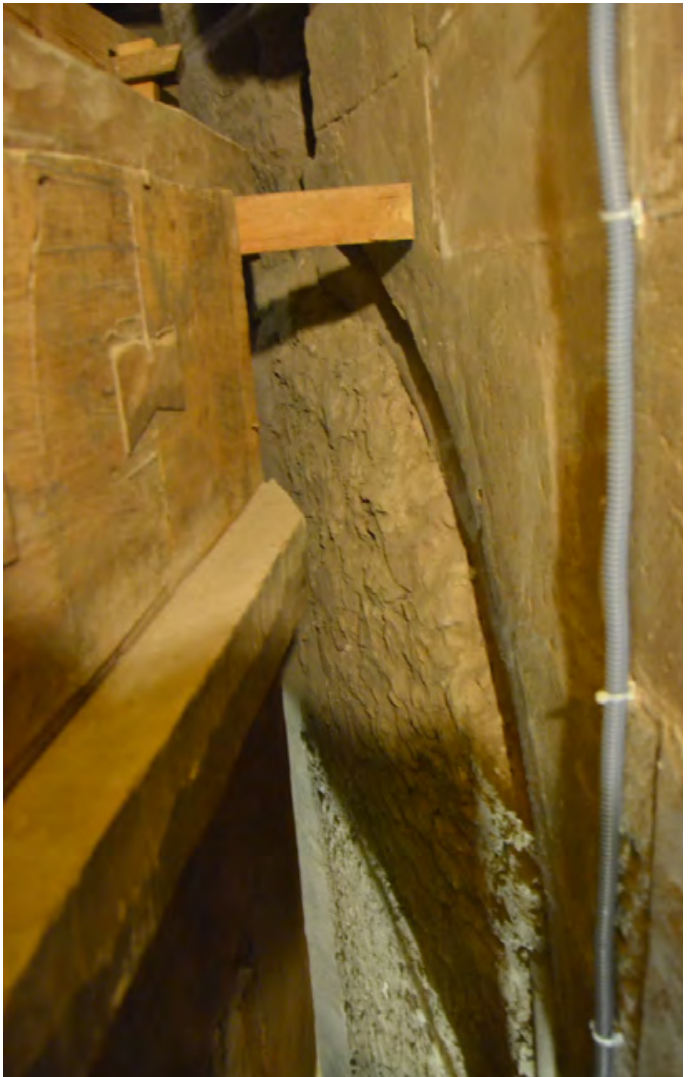

- Fig. 2. Catedral de Sigüenza. Muro interno del ábside principal. Arco de enmarque y relleno de absidiola lateral. Foto de la autora.

\section{ESTADO DE LA CUESTIÓN}

Los estudios realizados sobre la catedral de Sigüenza han sido numerosos y en ellos se han ido analizando aspectos y periodos diferentes con el fin de aclarar el devenir de una estructura centenaria que fue cambiando a lo largo del tiempo 3 .

Por lo que respecta a la Historia del Arte medieval del templo, disciplina y periodo en el que nos vamos a centrar, se podría decir que desde la publicación, en 1865, del libro de G. E. Street Gothic Architecture in Spain, el edificio se revalorizó y el interés despertado

\footnotetext{
${ }^{3}$ Afortunadamente, hoy se puede contar con un compendio bibliográfico publicado en 2009 y que recoge las publicaciones con tema seguntino desde el siglo XVI hasta 2008, lo que nos evitará hacer grandes listas de referencias historiográficas, véase, A. BISLENGHI, La mesnada del Doncel. Bibliografía Seguntina de 1533 a 2008, Guadalajara, 2009.
} 


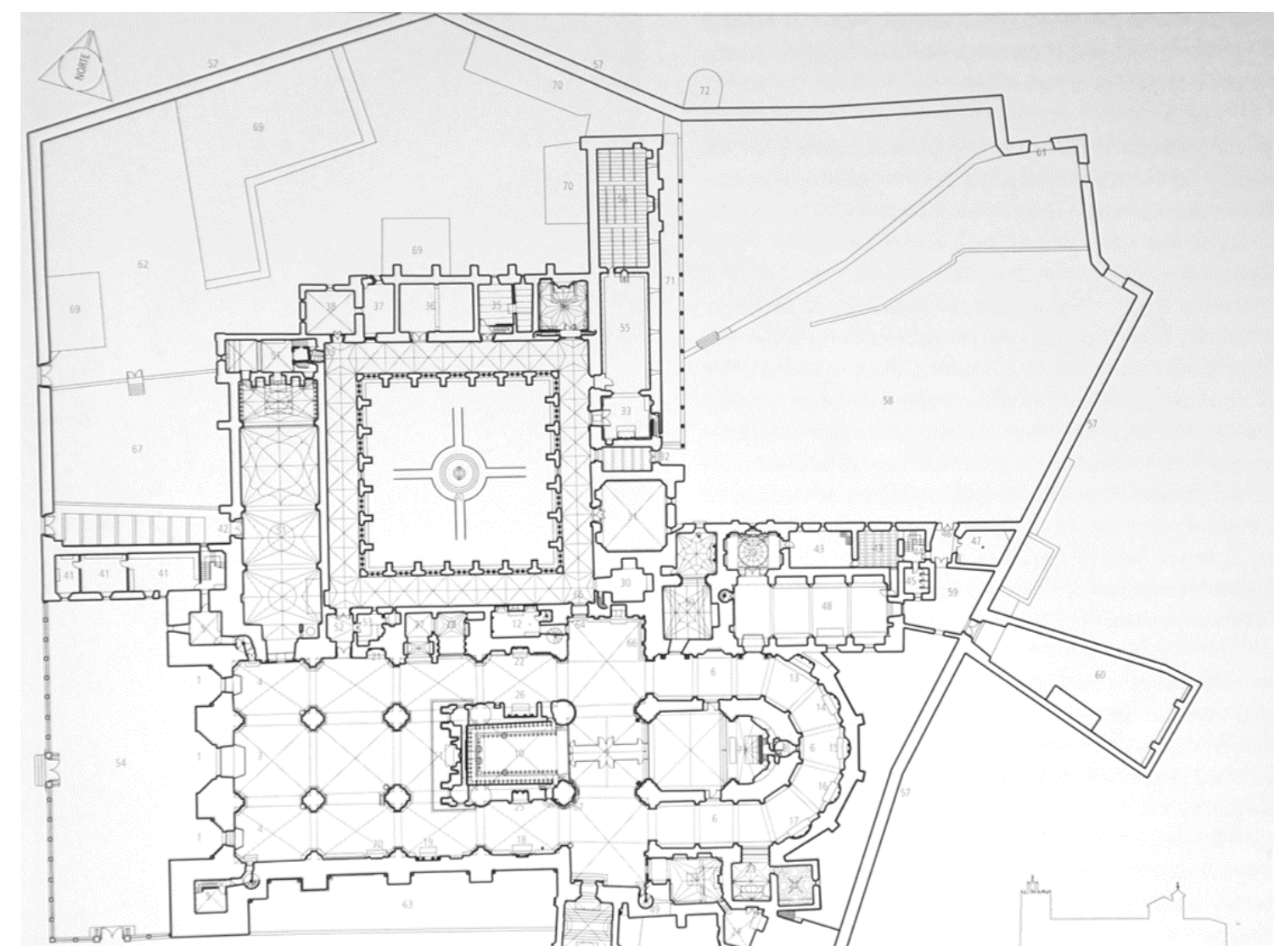

- Fig. 3. Catedral de Sigüenza. Planta. AA.VV., La catedral de Sigüenza. La puesta en práctica de un plan director, Barcelona, 2006, p. 27.

por el mismo no dejó de crecer entre los expertos $^{4}$. En este sentido, las obras de Manuel Pérez-Villamil o de Élie Lambert son un destacado ejemplo a tener en cuenta ${ }^{5}$.

El siguiente hito que debemos señalar es la publicación de la doctora Muñoz Párraga, fruto de su Tesis Doctoral ${ }^{6}$. En este trabajo se recogieron todos los aspectos histórico-artísticos susceptibles de ser desarrollados en

${ }^{4}$ Se ha utilizado la versión española del texto citado, G. E. STREET, La arquitectura gótica en España, Madrid, 1926, especialmente pp. 226-230.

${ }^{5}$ M. PÉREZ-VILLAMIL, La catedral de Sigüenza erigida en el siglo XII, Madrid, 1899 (la edición utilizada es la facsímil de 1984) y E. LAMBERT, L'Art Gothique en Espagne. Aux XIIe et XIIIe siècles, Paris, 1931, especialmente pp. 182-195 y 295.

${ }^{6}$ M. C. MUÑOZ PÁRRAGA, La Catedral de Sigüenza (Las fábricas románica y gótica), Guadalajara, 1987. En el apartado sexto de esta publicación se hallarán unos completos apéndices documentales y bibliográficos sobre la obra. aquel momento y, además, el enfoque que se le dio a la investigación, desde el punto de vista de los obispos patrocinadores, coincide con los intereses del Proyecto en el que se inserta este artículo.

Como colofón a este selectivo repaso historiográfico, tenemos que añadir que, desde los últimos años noventa, los trabajos en relación con el Plan Director para la restauración y conservación de la catedral seguntina condujeron, de nuevo, a una revisión histórico-artística y técnica, con el añadido de excavaciones, prospecciones y mediciones complejas. Todo ello fue documentado convenientemente y dio pie a otra Tesis, la del doctor arquitecto Juste Ballesta, con la consiguiente publicación de referencia sobre la iglesia mayor de Sigüenza ${ }^{7}$.

${ }^{7}$ La Tesis del doctor Juste Ballesta se leyó en la Universidad Politécnica de Madrid en el año 2007 con el título Transformación y Restitución de la Catedral de 
Respecto a la cuestión central que nos va a ocupar, el trazado pensado en el siglo XII para la zona oriental del templo catedralicio, tenemos que precisar que el aspecto que hoy conserva el edificio, a causa de la realización de la girola a finales del siglo XVI, ha hecho muy difícil el conocimiento de ese testero (Fig. 3) ${ }^{8}$. Por ello, las propuestas para la cabecera se han visto vinculadas, razonablemente, a modelos románicos de tradición benedictina, cinco ábsides escalonados, con profundidades decrecientes hacia los extremos, que, además, coinciden con las advocaciones de los cinco altares principales que aparecen documentados a finales del siglo XII ${ }^{9}$. Esta solución, que ya aparece en los estudios sobre el edificio del siglo XIX, es la que han seguido, generalmente, los investigadores hasta hoy (Fig. 4$)^{10}$. Pues, por otra parte, los trabajos de Torres Balbás en el templo dejaron traslucir que se llegó a hacer

Sigüenza y su entorno urbano. Además, véase AA.VV., La catedral de Sigüenza. La puesta en práctica de un Plan Director, Barcelona, 2006. Por otra parte, en el Archivo del Instituto de Patrimonio Cultural de España (en adelante AIPCE) se pueden revisar los informes histórico-artísticos y técnico-arqueológicos relacionados con el Plan Director de la catedral seguntina, desde los estudios previos de 1990 al Plan definitivo de 1998. En estos trabajos se incluyeron también los documentos conservados de las restauraciones que se hicieron entre 1937 y 1948, tras los desastrosos efectos de la guerra. Obras dirigidas principalmente por los arquitectos L. Torres Balbás y A. Labrada Chércoles. Por otra parte, en el mismo archivo, se guardan otros testimonios menores de intervenciones llevadas a cabo en el edificio y su entorno desde 1970.

8 M. C. MUÑOZ PÁRRAGA, “Transformación de la cabecera de la catedral de Sigüenza: la obra de la Girola y sus Maestros Constructores", Ábside, 1, 1987, pp. 12-18.

${ }^{9}$ Nos referimos a los datos que se conservan en relación con la institución de la sacristanía por el obispo don Rodrigo (1192-1221) y su aprobación por el Papa Celestino III en 1197. Las dedicaciones de dichas aras eran, de norte a sur, San Juan Bautista, San Agustín, Santa María, Santos Pedro y Pablo y Santo Tomás de Canterbury, véase M. C. MUÑOZ PÁRRAGA, La catedral..., pp. 89-90, 129-130 y plano anexo.

${ }^{10}$ Desde la obra de M. PÉREZ VILLAMIL, Op. cit., pp. 72 y 84-85 hasta los trabajos del siglo XXI, AA. VV., Op. cit., p. 33.

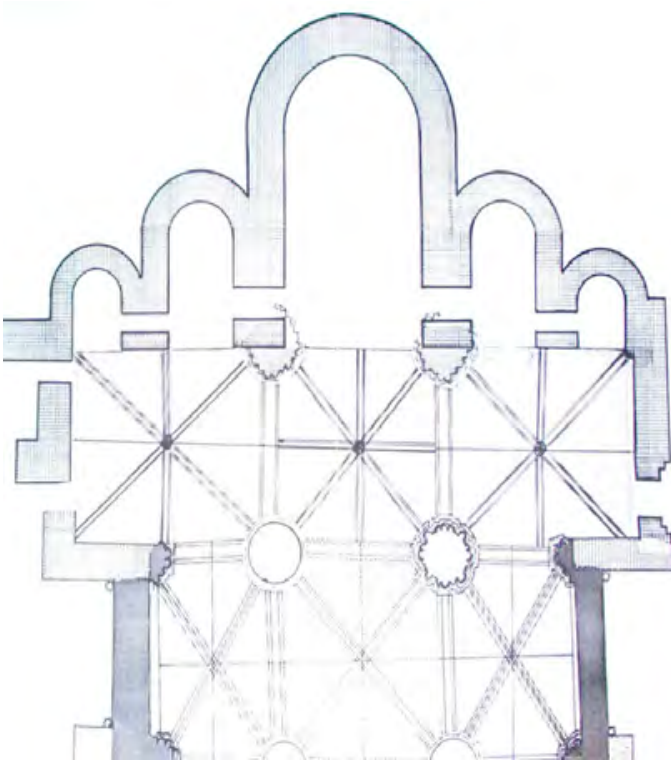

- Fig. 4. Catedral de Sigüenza. Planta en M. C. MUÑOZ PÁRRAGA, La catedral de Sigüenza (Las fábricas románica y gótica), Guadalajara, 1987, plano II.

alguna excavación que probaba la existencia de dichos ábsides ${ }^{11}$.

A pesar de todo lo dicho, en algún caso reciente se ha puesto en tela de juicio este diseño, pues se ha pensado que el razonamiento que lo ha sustentado no era definitivo, $y$, además, a esto se añadía que no se habían podido contrastar los perfiles de las cuatro capillas laterales del presbiterio en el subsuelo, con los nuevos métodos de análisis y detección de paramentos ${ }^{12}$.

${ }^{11}$ Cuestión recogida en, AA. VV., Op. cit., p. 95.

${ }^{12} \mathrm{El}$ asunto de las dudas razonables sobre los cinco ábsides está muy bien explicitado en el "Estudio arqueológico y archivo catedralicio" del Plan director de la catedral de Sigüenza (AIPCE, PD-34(7/8)) que firmó M. Presas Vías en noviembre de 1998. En este trabajo, en las páginas 34 a 36 se analizan los argumentos esgrimidos por la doctora Muñoz Párraga (La catedral..., pp. 89,110 y 326) que había señalado un arco tapiado tras el mausoleo de don Fadrique de Portugal, situado en el lado Este del brazo Norte del transepto, como posible resto de la entrada al ábside dedicado a San Juan Bautista, $y$, por otra parte, había afirmado que en la capilla llamada hoy del Doncel, en el brazo sur del crucero, había evidencias del ábside dedicado a Santo Tomás de Canterbury. El señor Presas Vías considera que dichos argumentos no son definitivos. 
Por otra parte, al estudio y conocimiento de la cabecera seguntina hay que añadir algunos detalles interesantes aportados por Pérez-Villamil, pero que no le hicieron cambiar de idea sobre las cinco absidiolas en batería. Me refiero a las alusiones a "ciertas hornacinas que se notan en el muro del ábside por detrás del presente retablo" y a que "a espaldas del altar mayor existe una grande y profunda hornacina que debió de ser el fondo del ábside primitivo, donde se alzaba la silla o cátedra episcopal y en cuya concavidad se hizo posteriormente una habitación, que después de haber servido de archivo, hasta 1514 fue convertida en oratorio para la reserva del sacramento". Apunta también el autor que el lugar se cerró, a modo de camarín, con una reja dorada desde $1526^{13}$.

Por si fuera poco, el mismo investigador llegó a escribir que: "En el siglo XIII los cinco ábsides quedaron reducidos a tres; pero conservando los cinco altares primitivos", sin que aporte datos específicos sobre esta afirmación ${ }^{14}$.

Carmen Muñoz también había resaltado que al construir la girola se comenzó por el lado del evangelio, ya que se dispuso que se derribase para ello la capilla de San Agustín en una reunión del Cabildo de 1569; además, otra noticia del Diario y Directorio del Coro, 1581-1610, hablaba de la capilla de San Pedro Apóstol, que estaba en el lado de la epístola, "donde ahora es la entrada del trascoro", véase M. C. MUÑOZ PÁRRAGA, La catedral..., p. 92.

Por otra parte, las conclusiones y recomendaciones de la campaña de geo-radar que se redactaron en junio de 2005 (AIPCE, Pl-1284) dicen textualmente que: "De cara a la localización y caracterización de los ábsides en el subsuelo podemos concluir que los datos aportados, sin ningún tipo de contrastación, reflejan gran cantidad de interferencias entre estructuras de muy diferente carácter.... El procedimiento recomendado para completar el alcance arqueológico de dichas anomalías es la realización de pequeñas catas $\mathrm{y}$, una vez determinado a qué estructura corresponden, se deberá tomar la decisión de si son de interés para los objetivos del proyecto...".

${ }^{13}$ M. PÉREZ VILLAMIL, Op. cit., pp. 211, 215 y 216. La cubierta que se hizo para ese espacio reaprovechado es perfectamente visible hoy. Ocupa la cuenca de la absidiola y sobresale, ligeramente, hacia la posición del retablo, véase la Fig. 1.

${ }^{14}$ Ibídem, p. 204
A estos antecedentes debemos añadir las imágenes que tomaron los restauradores del retablo mayor de la catedral, ya que fueron ellos los que accedieron al testero antiguo, entre 2009 y 2011, con el fin de limpiar y asegurar la parte trasera de la obra. Desafortunadamente no se explicitan en sus informes detalles más concretos sobre el paramento pétreo y sus particularidades, como son las hornacinas tapiadas ${ }^{15}$.

Por lo que respecta a las fechas propuestas para la realización de la cabecera catedralicia, estas se han visto muy mediatizadas por el único documento conservado que especifica algún dato concreto sobre la construcción. Me refiero a la donación del segundo obispo seguntino, Pedro de Leucata (1152-1156), quien en 1156 donó al cabildo la mitad de todos los derechos episcopales sobre Molina y lo que procediese de las salinas, pero aclarando que los réditos de estas últimas se reservarían para la fábrica de la iglesia, hasta que las cabezas de los altares y la cruz de toda la iglesia estuviesen íntegramente construidos ${ }^{16}$. A partir de esta noticia se ha supuesto, razonablemente, que los trabajos para construir la catedral se llevarían a cabo a partir de la segunda mitad del siglo XII.

${ }^{15}$ AIPCE. Legajo 571/2, Proyecto e Informe de Restauración del Retablo Mayor de la Catedral de Sigüenza (Guadalajara), 2011. En este documento, firmado por Francisca Azucena García Hernández, se publican fotografías de ménsulas y capiteles de la cabecera medieval, página 80 , así como una imagen antigua de la capilla mayor sin retablo, página 71 . En la página 245 , donde se habla de la revisión de la trasera, se ve una fotografía con un arco del remate superior tapiado de una de las absidiolas y en la página 433 se incluye la imagen donde un restaurador limpia la parte externa de la bóveda incluida en la absidiola central, a la que llaman, pertinentemente, "cupulín del camarín". En la página 470 aparece otra fotografía de un arco en bocel que enmarca una de las absidiolas laterales. Nada se dice de lo que significan estas exedras cegadas en el muro semicircular de la cabecera primitiva.

${ }^{16}$ T. MINGUELLA y ARNEDO, Historia de la Diócesis de Sigüenza y sus obispos, Madrid, 1910-1913, 3 vols., en este caso, vol. I, doc. no XLII, p. 398; H. YABÉN, Catálogo del Archivo Catedralicio de Sigüenza, con algunos documentos inéditos, Pamplona, 1939, doc. no 32, p. 15; M. PÉREZ VILLAMIL, Op. cit., p. 53 y M. C. MUÑOZ PÁRRAGA, La catedral..., pp. 47-48. 
EL MARCO HISTÓRICO-DOCUMENTAL DEL PRIMER OBISPO DE SIGÜENZA EN EL SIGLO XII. LOS REYES Y EL PRELADO

Con el fin de esclarecer el panorama en el que se gestó la construcción de la catedral seguntina, tras la recuperación definitiva del obispado por el Reino de León y Castilla en el primer tercio del siglo XII, se intentará hacer una revisión de los datos históricos conservados en relación con los primeros decenios de la vida episcopal en dicho centro. Ese inicial periodo estuvo ligado a la figura de Bernardo de Agen (†1152) quien se hizo cargo de la diócesis desde los años veinte del siglo XII hasta 1151.

La carrera del citado personaje en el Reino de León y Castilla se inició, posiblemente, como chantre de la catedral de Toledo y se vinculó muy pronto a la corte, donde ocupó algún cargo de confianza, como el de capellán y notario del heredero Alfonso Raimúndez, y así aparece en la documentación conservada desde el año $1123^{17}$. En ese contexto de poder, fue nombrado obispo de Sigüenza cuando el arzobispo Bernardo de Sédirac lo consideró oportuno, con el fin de lograr la adscripción de dicha sede a la mitra toledana y facilitar la reforma y la influencia

${ }^{17}$ R. JIMÉNEZ DE RADA, Historia de los hechos de España, edición de J. Fernández Valverde, Madrid, 1989, pp. 252-253; B. F. REILLY, The Kingdom of León-Castilla under Queen Urraca (1109-1126), Princeton 1982, pp. 171 a 178; I. RUIZ ALBI, La reina doña Urraca (1109-1126): Cancillería y colección diplomática [recopilación y estudio], León, 2003, doc. $\mathrm{n}^{\mathrm{o}}$ 100; M. LUCAS, Las cancillerías reales 1109-1230, León, 1993, pp. 83, 117 y 218; L. M. VILLAR GARCÍA, Documentación medieval de la catedral de Segovia (1115-1300), Salamanca, 1990, docs. 10, 18, 19 y 27, pp. 53, 60, 62 y 73; P. A. OLEA ÁLVAREZ, Sigüenza entre las dos Castillas y Aragón. Historia social, política y religiosa de las tierras de su obispado hasta 1300, Bilbao, 2009, pp. 180-181 y A. GAMBRA, Alfonso VI. Cancillería, Curia e Imperio, 2 vols., León, 1997, vol. II, p. 393; el doctor Gambra señala que en un documento de Toledo [1098-1099], conservado a través de una copia del siglo XII, donde se recoge una donación de Alfonso VI al monasterio de San Servando de la ciudad del Tajo, aparece entre los confirmantes un Bernardus, junto a otros posibles franceses, y el autor se pregunta si no podría ser Bernardo de Agen, miembro del círculo del arzobispo toledano. pontificia ${ }^{18}$. Pero, además, la recuperación de la sagontine ecclesie se insertó de lleno en la política regia de la primera mitad del siglo XII. La zona era frontera con el territorio islámico y con el Reino de Aragón, las crónicas y algún documento de Alfonso VII inciden en que ya había sido reconquistada por Alfonso VI, aunque no se consolidó, pero ahora, en época de la Reina Urraca, resultaba esencial asegurar este límite oriental del reino y doblemente conflictivo ${ }^{19}$.

El prelado seguntino era de origen aquitano y perteneció a una familia de clérigos que llegaron a ocupar varias cátedras hispanas en el siglo XII. Su tío, Pedro de Agen, fue obispo de Segovia desde 1119 hasta 1149 y un hermano, llamado Pedro, ocupó la silla episcopal palentina entre 1139 y 1147. El mismo Bernardo, al final de su vida, fue promocionado al arzobispado compostelano donde moriría en $1152^{20}$.

${ }^{18}$ El caso del obispado de Sigüenza es comparable al del Burgo de Osma y así se explica en C. REGLERO, "El Obispado de Osma hasta mediados del siglo XIII: Génesis y problemática”, en A. IRIARTE y L.V. DÍAZ MARTÍN (coords.), Santo Domingo de Caleruega. Contexto religioso. IV Jornadas de Estudios Medievales, Salamanca, 1996, pp. 183-224, especialmente p.186.

${ }^{19}$ R. JIMÉNEZ DE RADA, Op. cit., p. 174; T. MINGUELLA y ARNEDO, Op. cit., t. I, docs. II, IV y XX, pp. 348, 352 y 371; H. YABÉN, Op. cit., docs. 3 y 4, p. 7; B. F. REILLY, Op. cit., p. 326; A. de FEDERICO FERNÁNDEZ, "Catálogo descriptivo de los documentos reales en pergamino existentes en el archivo de la S. I. C. B. de Sigüenza", Investigación, 3, 1969, docs. 2 y 4, p. 7; M. RECUERO, Alfonso VII, Emperador. El Imperio hispánico en el siglo XII, León, 1979, p. 208 y M. LUCAS, Op. cit., pp. 228 y 229.

${ }^{20}$ Bernardo de Agen, en un documento de 1144, explica su parentesco con los otros obispos, véase $\mathrm{T}$. MINGUELLA y ARNEDO, Op. cit., t. I, pp. 55-94 y doc. XXIII, p. 375; AA.VV., Historia de las diócesis españolas, Iglesias de Palencia, Segovia y Valladolid, vol. 20, Madrid, 2004, pp. 221 y 600; I. RUIZ ALBI, Op. cit., pp. 450, 465, 553 y 575, de este último estudio se ha podido deducir que el obispo Pedro de Palencia pertenecía al círculo de la reina y durante toda su vida confirmó los documentos de la cancillería real, proximidad que será recompensada con donaciones por parte del monarca; C. de AYALA, Sacerdocio y reino en la España Altomedieval: Iglesia y poder político en el occidente peninsular, siglos VIIXII, Madrid, 2008, p. 377; AA.VV., Historia de las diócesis 
Sobre el momento en el que Bernardo fue consagrado obispo hay pocas seguridades, a no ser la referencia que él mismo hace a los 23 años de su ordenación en el documento citado de 1144 por lo que, posiblemente, en 1121 o 1122 obtendría el ordenamiento episcopal ${ }^{21}$. Por otra parte, no se debe olvidar que en los años 1122-1123, Alfonso de Aragón y Alfonso Raimúndez llegan a algún tipo de entendimiento político, con el apoyo de Bernardo de Toledo. En este contexto se pudo haber propiciado en Sigüenza la renovación de la diócesis para la que se eligió un prelado de los círculos del arzobispo y del futuro rey Alfonso VII'22. De cualquier modo, en el Concilio de Valladolid, celebrado en la segunda mitad de 1123 o principios de 1124, ya aparece Bernardo de Sigüenza suscribiendo decretos ${ }^{23}$.

españolas, Iglesias de Santiago de Compostela y Tuy-Vigo, vol.14, Madrid, 2002, pp. 54 y 521 y A. LÓPEZ FERREIRO, Historia de la Santa A. M. Iglesia de Santiago de Compostela, t. IV, Santiago de Compostela, 1901, pp. 248-253 y apéndices pp. 57-59.

${ }^{21}$ T. MINGUELLA y ARNEDO, Op. cit., t. I, p., 63, se inclina por el año 1121 e H. YABÉN, Op. cit., doc. 20, p. 12 , opina que el nombramiento del obispo se produjo en 1122. En la documentación de la catedral de Segovia, el obispo Bernardo aparece confirmando un documento, de 1122, como episcopus in Segoncia, véase L. M. VILLAR GARCÍA, Op. cit., doc. 7, p. 50.

${ }^{22}$ C. de AYALA, Op. cit., pp. 407-408. Sobre la fecha de la recuperación de Sigüenza y sus inicios complejos, véase $A$. URBIETO ARTETA, "Los primeros años de la diócesis de Sigüenza", en Homenaje a J. Vincke, Madrid, 1962-1963, pp. 135-148; A. BLÁZQUEZ, El señorío episcopal de Sigüenza: Economía y sociedad (1123-1805), Guadalajara, 1988, pp. 28 y 44-47; T. MINGUELLA y ARNEDO, Op. cit., t. I, p. 65; H. YABÉN, Op. cit., p. 7; E. LOBATO YANES, Urraca I. La corte castellano-leonesa en el siglo XII, Palencia, 2000, p. 180. Yabén y Blázquez piensan que se reconquistó Sigüenza en 1123 y Lobato añade que se hace con ayuda de Fernando García de Hita, alcalde de Medinaceli y Guadalajara, esposo de Estefanía Armengol, prima de la reina Urraca, que estaba establecido en el Trans-Duero y Noreste de Toledo, en P. A. OLEA ÁLVAREZ, Op. cit., pp. 179-193, se explica el asunto de la conquista de Sigüenza con toda su discusión actual.

${ }^{23}$ C. de AYALA, Op. cit., pp. 409-411 y G. MARTÍNEZ DÍEZ, Legislación conciliar del Reino Astur (718-910) y del Reino de León, León, 2009, pp. 251 a 256.
Lo cierto es que legendariamente se viene responsabilizando al primer prelado de la toma de Sigüenza en 1124, hecho que fue conmemorado históricamente por el cabildo el día 22 de enero, jornada en la que se hacía una procesión desde la catedral hasta la iglesia de san Vicente, ubicada en la zona alta de la ciudad, para señalar la entrada de los cristianos en la villa y honrar al santo en su festividad $^{24}$.

A todo lo expuesto hay que añadir, para intentar fijar las fechas de inicio de actividad en la Sede, que el primer documento que se conserva, dedicado específicamente a ella, se fechó el día primero de febrero de 1124 y salió de la cancillería de la reina de León y Castilla. A este diploma se le ha considerado como el que marcó la reconstitución del episcopado con una dotación inicial ${ }^{25}$. Doña Urraca concedió a la Iglesia diocesana y a su obispo Bernardo y sucesores, en perpetuidad, las décimas de todos los portazgos, quintos y alcabalas de Atienza y Medinaceli. El motivo de tal donación se explicitó diciendo que la Iglesia de Sigüenza había permanecido, durante 400 años, destruida y

${ }^{24}$ Véanse T. MINGUELLA y ARNEDO, Op. cit., t. I, p. 65; H. YABÉN, Op. cit., doc. 1, p. 7; M. C. MUÑOZ, La catedral..., pp. 21-24; P. MARTÍNEZ TABOADA, “Desarrollo urbanístico de las ciudades episcopales: Sigüenza en la Edad Media", en La Ciudad Hispánica, Madrid, 1985, pp. 957-971; A. BLÁZQUEZ, Op, cit., pp. 46-47.

${ }^{25}$ El pergamino, escrito en letra carolina, se conserva en el archivo de la catedral de Sigüenza. Además, su texto se trasladó al Cartulario recopilado a principios del siglo XIII durante el episcopado de don Rodrigo (11921221), véanse T. MINGUELLA y ARNEDO, Op. cit., t. I, pp. 347-348; H. YABÉN, Op. cit., doc. 1, p. 7; I. RUIZ ALBI, Op. cit., doc. 138, p. 575; M. LUCAS, Op. cit., p. 83; B.F. REILLY, Op. cit., p.179 y nota 79; E. LOBATO YANES, Op. cit., p. 182; A. de FEDERICO FERNÁNDEZ, “El archivo-biblioteca de la S.I.C.B. de Sigüenza”, Revista Archivos, Bibliotecas y Museos, t. LXVIII, 2, 1960, pp. 365-381, especialmente, p. 370; ÍDEM, “Catálogo descriptivo...", pp. 5-48, especialmente p. 7. Sobre el Cartulario, véase, C. SÁEZ “Ordenar y conservar en la catedral de Sigüenza (siglos XII-XIII)", Anexos de Signo 4, 2004, pp. 75-92 y C. SÁEZ y A. E. GUTIERREZ, “De la austeridad a la ostentación: los cartularios de Celanova y Sigüenza", en Silos. Un Milenio, vol. III Cultura, Burgos-Silos, 2003, pp. 211-225. 
desolada por la impiedad de los sarracenos. La dádiva la ofrece la reina por voluntad espontánea y para el remedio de sus pecados y de las almas de sus antepasados, el rey Alfonso (VI) y la reina Constanza.

La información que nos proporciona dicho documento es valiosísima, ya que se conceden medios materiales a la diócesis para poder reorganizarse y se señala, además, la situación de penuria en la que se encontraba. Por lo tanto, tenemos un primer apoyo patrocinador en la figura del monarca e inmediatamente el obispo tendrá que poner en marcha la sede. En este contexto, será necesario acondicionar ciertos espacios para el normal desarrollo de la liturgia y de la vida de los eclesiásticos que la asisten.

El documento de 1124 fue confirmado por Alfonso Raimúndez y por una serie de prelados, presididos por Bernardo de Toledo, entre los que se encontraban Pedro de Segovia, Pedro de Palencia y Raimundo de Osma; todos ellos ligados al arzobispo y sus orígenes, la zona gascona de la Sauvetat y el monasterio de San Orencio de Auch ${ }^{26}$. El diploma parece indicar que el renacimiento de la sede se hace con la aquiescencia del poder civil y religioso del reino leonés y castellano.

En los años sucesivos la corona ayudó al obispo Bernardo de Agen constantemente, así el rey Alfonso VII, circa 1126, confirmó lo donado por su madre en Atienza y Medinaceli, a lo que añadió San Justo con sus aldeas. De allí obtendrán las décimas del pan, vino, sal, portazgos y huertos, pero, además, las quintas de los molinos, de la alcabala y de todo lo que al rey pertenezca. También le concedió el molino real, situado entre el majuelo del obispo y la tierra de Santa María de Medina, con su torre y todo lo suyo. Por otra parte, confirmó una compra, de 1125, hecha por el prelado seguntino a Pedro Ciprianiz en Medinaceli; en ella se incluye una casa

${ }^{26}$ Para el caso de Osma, véase C. REGLERO, Op. cit., p. 186 y T. PORTILLO CAPILLA, "La Regla de San Agustín en la catedral de Santa María de Osma" en A. IRIARTE y L. V. DÍAZ MARTÍN (coords.), Op. cit., pp. 225-244, especialmente pp. 226-229. con corral más su horno, un molino y unas salinas, por lo que pagó 270 mencales $^{27}$. La finalidad de la dádiva regia fue el sustento del obispo y la reedificación de la Iglesia, en sentido lato, lo que incluiría la idea de hacer una catedral. Pero, por otra parte, se advierte que don Bernardo ya va pudiendo acrecentar el patrimonio de su obispado en una de las villas de las que recibía réditos y lo hace con dinero.

La ampliación del patrimonio episcopal continúa con otra concesión del rey, posiblemente de 1129, relativa al castillo de Santiuste y la villa de la Riba, con sus salinas, puertos, prados, torres, molinos, montes, fuentes... ${ }^{28}$. Todos estos lugares donados, Atienza, Medinaceli, San Justo, son plazas fuertes situadas en la línea septentrional del episcopado, con todo su carácter militar y defensivo.

La carta de 1129 recoge otro dato importante de la organización de la sede, pues se dirige a la Iglesia de Santa María, al obispo don Bernardo y sucesores, más a los canónigos que la sirven, lo que indica un cabildo con un ordenamiento. Además, el

${ }^{27}$ Todas estas referencias documentales se conservan únicamente en el Cartulario de la Catedral de Sigüenza, por lo tanto se deben asumir con toda su problemática. Véase, T. MINGUELLA y ARNEDO, Op. cit., t. I, docs., III y IV, pp. 349 y 351; H. YABÉN, Op. cit., doc. 2, p. 8. Además, el Cartulario incluye la confirmación real de la donación citada, que se hizo en el mes de junio de 1135 en la ciudad de Toro, véase T. MINGUELLA y ARNEDO, Op. cit., t. I, p. 350.

${ }^{28}$ T. MINGUELLA y ARNEDO, Op. cit., t. I, doc., II, p. 348; H. YABÉN, Op. cit., doc. 3, p. 8; A. de FEDERICO FERNÁNDEZ, "Catálogo descriptivo...", doc. 2, p. 7. El documento, tanto el considerado original, como su copia en el Cartulario, tiene problemas de datación, pues se fecha en 1124. Los investigadores creen que es probable que se hiciese en 1129, véase M. LUCAS, Op. cit., p. 228 , donde se especifica que los obispos y el mayordomo real nos llevan a 1129. El documento fue confirmado por el rey el 7 de febrero de 1130, en el contexto del Concilio de Carrión, y se conserva un original y su copia en el Cartulario de Sigüenza, véanse T. MINGUELLA y ARNEDO, Op. cit., t. I, doc., VI, p. 352; H. YABÉN, Op. cit., doc. 4, p. 8; A. de FEDERICO FERNÁNDEZ, “Catálogo descriptivo...", doc. 4, p. 7; A. RECUERO, Op. cit., p. 208 y M. LUCAS, Op. cit., p. 229. 
rey lo da a perpetuidad, por el alma de sus padres, la remisión de sus pecados y para que su memoria se recuerde siempre allí. Un tema de cierta trascendencia, ya que se manifiesta el interés del monarca para que su figura no se olvide y esté siempre ligada a este obispado.

En esta línea de donaciones reales se encuentra también, en estos años veinte del siglo XII, el asunto de Soria, que pasó efímeramente a Sigüenza y fue motivo de discordia con Osma; hasta que tras el Concilio de Burgos, de 1136, se incorporó definitivamente a la sede oxomense ${ }^{29}$. Pero, además, el monarca concedió, en ese mismo diploma, las salinas regias destruidas de Medinaceli, para que se reedifiquen ${ }^{30}$.

Durante esos primeros años de recuperación, el obispado recibió réditos de la hacienda real y de algunas propiedades situadas en la zona norte del episcopado, patrimonio que se vio tímidamente incrementado gracias a las compras realizadas por el mismo obispo. Pero nada sabemos de la instalación material del grupo episcopal, de la edificación de la catedral, ni de las dependencias necesarias para los clérigos que la atienden.

\footnotetext{
${ }^{29}$ A pesar de los pocos años que Soria dependió del obispo Bernardo de Agen, se puede rastrear su influjo, pues en un documento de donación de la infanta doña Sancha al Monasterio de Sahagún, del año 1130, al prelado citado se le pone el apelativo de Numantinus al confirmar la carta, véase, J. A. FERNÁNDEZ FLÓREZ, Colección diplomática del monasterio de Sahagún, León, 1991, t. IV (1110-1199), doc. 1239, p. 123. Por otra parte, el contencioso Osma-Sigüenza por Soria ha sido muy estudiado, véase la bibliografía pertinente a través, por ejemplo, de la Historia de las Diócesis Españolas de la Biblioteca de Autores Cristianos y en C. REGLERO, Op. cit. de la nota 29.
}

${ }^{30} \mathrm{El}$ documento que se conserva en el archivo de la catedral de Sigüenza, sobre estos asuntos, es una copia del s. XII y, además, fue trasladado al Cartulario, véase T. MINGUELLA y ARNEDO, Op. cit., t. I, doc., IV, p. 351; H. YABÉN, Op. cit., doc. 2, p. 7; A. de FEDERICO FERNÁNDEZ, "Catálogo descriptivo...", doc. 3, p. 7; M. LUCAS, Op. cit., doc. 74 , p. 225 , este último autor duda sobre la fecha del diploma y propone adelantarlo a 1124 .
En la siguiente década, los años treinta del siglo XII, al aumento de derechos y propiedades, casi siempre donaciones de Alfonso VII, tenemos que restar ciertas pérdidas provocadas por desacuerdos con las diócesis vecinas a propósito de límites o injerencias específicas sobre lugares concretos. Hay que señalar, por otra parte, que nos encontramos aún en zona de frontera y que hasta la muerte de rey de Aragón, Alfonso I, en 1134, la inestabilidad de estas tierras orientales del reino de León y Castilla fue una constante.

De las citadas dádivas del monarca señalaremos en primer lugar la que se recogió en un documento de junio de 1135 por el que concede, al obispo y los canónigos que allí sirven, las décimas y todos los réditos reales de Calatayud con los palacios reales que están al lado de la iglesia de Santa María y los baños. Además, añade Villafeliz con sus términos y Salas, que estaba recién repoblada por Alfonso de Aragón y se situaba entre Ágreda y Ólvega. Por otra parte, les da las décimas y réditos reales de Santa María de Bonmai en Soria y lo mismo en Almazán, con el añadido de las aceñas, casas, huertos y todo lo que fue del capellán del rey aragonés Enegoni ${ }^{31}$.

Este aumento de ingresos y la paz política que se respiraba, tras la muerte del Batallador (†1134), permitirían al obispo vislumbrar la viabilidad de sus ideas en relación con la organización la sede ${ }^{32}$. De este

${ }^{31}$ El diploma es una copia, posiblemente del siglo XII, que fue autentificada, más tarde, por el arzobispo toledano don Rodrigo Jiménez de Rada (1209-1247). Además, está en el Cartulario seguntino, véanse T. MINGUELLA y ARNEDO, Op. cit., t. I, doc., VII, p. 354; H. YABÉN, Op. cit., doc. 7, p. 9; A. de FEDERICO FERNÁNDEZ, "Catálogo descriptivo...", doc. 7, p. 8; M. LUCAS, Op. cit., doc. 201, p. 241.

Dentro del espacio dedicado a "pérdidas" para el episcopado, podemos añadir que el monarca, en 1133, donó al monasterio de San Salvador de Oña unas sernas emplazadas en Sigüenza, que, al parecer, no dañaban mucho a la diócesis incipiente, pues no se han rastreado conflictos entre ambas instituciones, véase, M. LUCAS, Op. cit., doc. 163, p. 236.

32 Está claro que el prelado contaba, incondicionalmente, con el amparo de Alfonso VII, de cuyo círculo no 
modo, en julio de 1135, instituyó las colegiatas de Medinaceli y Calatayud con la cesión de importantes bienes para su honesta sustentación $^{33}$. Gracias a este texto se conoce a algunos de los miembros del clero catedralicio, como Donatus, archidiácono, Forto prior y Willelmus, clérigo. Además, Pedro Ausciensis, posiblemente de Auch, escribió la carta.

De nuevo, la relación del prelado con el sur gascón es evidente y la organización del cabildo, con hombres de variada procedencia, es un hecho.

Tres años más tarde, el 16 de septiembre de 1138, el monarca de León y Castilla concedió al obispo Bernardo el lugar donde estaba fundada la iglesia episcopal de Sigüenza, con todas las heredades que a ella pertenecían. Además, autorizó que se instalasen allí 100 casados con sus familias, para ayudar a poblar y ponerse al servicio del prelado ${ }^{34}$.

En una segunda carta firmada en Almazán, el mismo día y año, según reza el Cartulario, el rey donó a la iglesia de Sigüenza y a su obispo, para la sustentación de la misma y de sus prelados, la villa de Serón con sus términos y pertenencias, incluidos los moros

se desvinculó, pues, por ejemplo, el 5 de diciembre de ese mismo año, 1135, don Bernardo confirmaba una donación del monarca al Monasterio gallego de Tojosoutos y seguía firmando como capellán del emperador y obispo de Sigüenza, véanse M. RECUERO, Documentos medievales del reino de Galicia. I. Alfonso VII (1116-1157), La Coruña, 1998, doc. 60, p. 60 y M. LUCAS, Op. cit., doc. 213, p. 242

${ }^{33}$ El pergamino original, conservado en el archivo de la catedral de Sigüenza, está desgastado y es difícil de leer, véanse T. MINGUELLA y ARNEDO, Op. cit., t. I, doc., VIII, pp. 355-356 e H. YABÉN, Op. cit., doc. 8, pp. 9 y 10, en este último se hacen muchos comentarios sobre las particularidades del diploma.

${ }^{34} \mathrm{El}$ documento original no se conserva y sólo contamos con la copia del Cartulario. La trascendencia de esta donación es mucha, pues de ella deriva el señorío de los obispos sobre la ciudad, situación que se mantendrá hasta 1798, véanse T. MINGUELLA y ARNEDO, Op cit., t. I, doc., XV, pp. 364; M. C. MUÑOZ PÁRRAGA, La catedral..., p. 33; M. LUCAS, Op.cit., doc. 279, p. 251 y A. BLÁZQUEZ, Op. cit., pp. 42 y 49. y sus familias que allí vivían; a esto añadió la posibilidad de seguir poblándola con cristianos, a los que se les podía dar el fuero que se considerase oportuno ${ }^{35}$.

En septiembre de 1139, Alfonso VII, de nuevo, concedió a Santa María de Sigüenza y al obispo Bernardo las décimas de todo el episcopado, especificando los lugares, y añadió los diezmos de las salinas de Bonilla e Imón, con normas para hacer sal y vender$1 a^{36}$.

Todas estas nuevas aportaciones a la diócesis fueron consolidando sus propiedades y derechos, situación que permitiría tener algún excedente para gastos extraordinarios.

A pesar de la buena marcha de la configuración del episcopado, los problemas respecto a los límites diocesanos se produjeron ya en los años treinta de la duodécima centuria. Estas cuestiones espinosas estuvieron unidas, además, al intento de que cada reino tuviese sus obispados y no hubiera demasiadas interferencias entre ellos ${ }^{37}$. En esta línea, se realizó una concordia, en 1135, entre Sigüenza y Zaragoza sobre Daroca y Calatayud; además, en 1136, en el concilio de Burgos, el legado pontificio, cardenal Guido, dictó sobre las fronteras entre Sigüenza, Osma y Tarazona. Desde ese momento Calatayud se incorporó a Tarazona, Soria a Osma y Sigüenza aclaró que tenía Almazán,

${ }^{35}$ T. MINGUELLA y ARNEDO, Op. cit., t. I, doc., XVI, p. 366; M. LUCAS, Op. cit., doc. 280, p. 251, este investigador opina que el nombre de la villa se debe leer como Lerón, no Serón; M. RECUERO, Alfonso VII..., p. 216 y M. C. MUÑOZ PÁRRAGA, La catedral..., p. 33.

${ }^{36} \mathrm{El}$ documento original se conserva en el archivo catedralicio de Sigüenza, véanse T. MINGUELLA y ARNEDO, Op. cit., t. I, doc., XVII, pp. 367 e H. YABÉN, Op. cit., doc. 12, p. 10; A. de FEDERICO FERNÁNDEZ, "Catálogo descriptivo...", doc. 9, p. 9; M. C. MUÑOZ PÁRRAGA, La catedral..., p. 34 y M. LUCAS, Op. cit., doc. 303, p. 254. A través de este documento se puede observar la importancia del crecimiento de la diócesis de Sigüenza hacia el Este, en territorio aragonés, con la villa de Molina como gran centro.

${ }^{37}$ C. REGLERO, “El obispado de Osma...”, p. 191. 
Ayllón, Caracena, Berlanga y Velamazán. Todas estas decisiones fueron corroboradas por el rey Alfonso VII ${ }^{38}$.

Posteriormente, será el papado el que dé fe de estos hechos en bulas de Inocencio II, circa 1139, y de Eugenio II en $1146^{39}$.

${ }^{38}$ Del diploma de 1135 se conservan en Sigüenza el original y otro ejemplar contemporáneo, en formato más pequeño, véase T. MINGUELLA y ARNEDO, Op. cit., I, doc., IX, p. 356. Todas estas resoluciones debieron ser cuidadosamente preparadas por Bernardo de Agen en el entorno episcopal y de la corte, así, en el marco de la coronación imperial de 1135 , en León, se pudieron llevar a cabo los acuerdos con Zaragoza, tal como explicaron los siguientes investigadores al estudiar el texto y su contexto: H. YABÉN, Op. cit., docs. 9-10, p. 10; M. RECUERO, Alfonso VII..., p. 212 y M. LUCAS, Op. cit., doc. 190, p. 239. Por otra parte, antes del concilio de Burgos de 1136, posiblemente celebrado en el mes de septiembre, se conservan algunos documentos donde aparece don Bernardo ligado a la corte y firmando cartas reales destinadas a beneficiar al monasterio de Sahagún y a las diócesis de Osma y Orense, véanse J. A. FERNÁNDEZ FLÓREZ, Op. cit., t. IV (1110-1199), doc. 1256, p. 148; J. LOPERRÁEZ CORVALÁN, Descripción Histórica del Obispado de Osma. Con el Catálogo de sus Prelados, Madrid, 1788, t. III, doc. XIV, p. 15 y M. RECUERO, Documentos medievales del Reino de Galicia. Alfonso VII..., doc. 65, p. 65 y M. LUCAS, Op. cit., pp. 78-79, en este último se hacen puntualizaciones sobre la data del documento orensano. Para las decisiones conciliares y la carta real se pueden ver, T. MINGUELLA y ARNEDO, Op. cit., t. I, docs., X-XI, pp. 358-359; H. YABÉN, Op. cit., doc. 11, p. 10; M. LUCAS, Cancillerías..., docs. 238 y 244, pp. 246 y 346; J. LOPERRÁEZ CORVALÁN, Op. cit., t. III, doc. 15, p. 16; G. MARTÍNEZ DÍEZ, Op. cit., pp. 304-305 y 310 y A. de FEDERICO FERNÁNDEZ, "Catálogo descriptivo...", doc. 8 , p. 8 .

${ }^{39}$ El obispo Minguella copió del cartulario seguntino dos bulas de Inocencio II y una carta a Alfonso VII del mismo pontífice y las fechó en 1138 , posteriormente F. Fita dio a los documentos la data de 1139 , cronología con la que está de acuerdo De Federico, véanse T. MINGUELLA y ARNEDO, Op. cit., t. I, docs., XII, XIII y XIV, pp. 361-363; F. FITA, "Bernardo de Agen, obispo de Sigüenza y el segundo concilio ecuménico de Letrán”, Boletín de la Real Academia de la Historia, LX, 1912, pp. 270-273; A. de FEDERICO FERNÁNDEZ, "El Archivo biblioteca...", pp. 365-381, especialmente, p. 371. Por otra parte, J. LOPERRÁEZ CORVALÁN, Op. cit., t. III, doc. XVI, p. 18, fechaba la bula de Inocencio II el 6 de marzo de 1137.

Para la bula de Eugenio II, T. MINGUELLA y ARNEDO, Op. cit., t. I, doc. XXIV, p. 378.
A partir de los años citados, el obispo -con la ayuda regia- conseguirá, entre 1140 y 1143 , consolidar el centro de su episcopado, dispondrá del patrimonio concentrándolo en los límites naturales de Castilla y contará con algo de moneda para entregar al monar$\mathrm{ca}^{40}$.

Todas estas condiciones ayudarían a instituir y dotar solemnemente el cabildo catedralicio el 26 de diciembre de 1144 y, en ese mismo diploma, se especificaron también los trabajos angustiosos que tuvieron que hacerse para reedificar la iglesia, tras muchos años destruida por los sarracenos. El escrito, que no es cancilleresco y pudo salir del entorno episcopal, no puede ser más explícito respecto a la erección de la iglesia

\footnotetext{
${ }^{40}$ De las noticias conservadas del año 1140 se desprende la libertad del obispo y su cabildo para disponer de ciertos bienes, como las fincas y aceñas que se le conceden vitaliciamente a Íñigo, antiguo capellán de Alfonso I de Aragón, al que se le admite, además, como canónigo, véanse T. MINGUELLA y ARNEDO, Op. cit., t. I, doc., XVIII, p. 369; H. YABÉN, Op. cit., doc. 16, p. 11 y M. C. MUÑOZ PÁRRAGA, La catedral..., p. 34; por otra parte, se hace un convenio entre el Concejo de Medinaceli y el obispo sobre los pobladores de Alcubilla y sus obligaciones, intentando igualarlas a las de Medina, consúltense, T. MINGUELLA y ARNEDO, Op. cit., t. I, doc., XIX, p. 370 y M. C. MUÑOZ PÁRRAGA, La catedral..., p. 34; además, el rey concede a don Bernardo y sus canónigos el derecho hereditario sobre los hombres que han poblado los alrededores de la iglesia (sede episcopal) y les da permiso para que puedan venir otros 100. Todos dependerán del obispo y les da el fuero de Medinaceli con normas procesales, véanse $\mathrm{T}$. MINGUELLA y ARNEDO, Op. cit., t. I, doc., XX, p. 371; H. YABÉN, Op. cit., docs. 13, 14, 15 y 17, pp. 11 y 12; M. C. MUÑOZ PÁRRAGA, La catedral..., p. 34; M. RECUERO, Alfonso VII..., p. 217; M. LUCAS, Op. cit., doc. 318, p. 256 y A. de FEDERICO FERNÁNDEZ, "Catálogo descriptivo...", doc. 10, p. 9. Por último, al intercambiar con el monarca Serón (o Lerón) por Caracena, el prelado le entrega 500 morabetinos y concentra las posesiones episcopales más al oeste, como cuando recibe la villa desierta de Aragosa con su castillo, que está al Sur, entre Sigüenza y tierra de moros, con el fin de poblarla, véanse, T. MINGUELLA y ARNEDO, Op. cit., t. I, docs. XXI-XXII, pp. 373-374; H. YABÉN, Op. cit., docs. 18-19, p. 12; M. C. MUÑOZ PÁRRAGA, La catedral..., p. 34; M. RECUERO, Alfonso VII..., pp. 218 y 221; M. LUCAS, Op. cit., docs. 324 y 376, pp. 257 y 263; A. de FEDERICO FERNÁNDEZ, "Catálogo descriptivo...", docs. 14-15 p. 10 y G. MARTÍNEZ DÍEZ, Op. cit., pp. 315-325.
} 
mayor. Pues dice: “...reedificata ecclesia et contra inimicorum impetum crucis Christi, duplici muro et turribus firmata". Por lo tanto, las obras del centro catedralicio eran un hecho, con dobles muros y torres bien cimentadas ${ }^{41}$.

A partir de aquí, el prelado se centró en dotar convenientemente un cabildo de religiosos, con el prior Bernardo al frente, que atenderían la Iglesia y seguirían las reglas de san Agustín y san Jerónimo. Hizo todo esto por su alma, las de sus padres y familiares, los obispos de Segovia y Palencia, y prescribió que se sustentase a dos pobres cotidianamente. Además, nombró las festividades más importantes a celebrar con pitanzas extraordinarias, Natividad, Resurrección, Pentecostés y Asunción de María, y no se olvidó de recordar al emperador que les cedió los derechos in perpetuum sobre todos esos bienes que él reparte a la mitad con los canónigos, pues, de otro modo, no podrían pagarse ni el comer ni el vestir. Por último, podemos añadir que, con este diploma, parece que se introduce el uso del sello en los documentos episcopales seguntinos, no debemos olvidar que Bernardo de Agen había sido miembro de la cancillería de Alfonso VII ${ }^{42}$.

El prelado, una vez organizada la sede de su episcopado, volvió a la Corte, para posteriormente desplazarse con el rey en su campaña militar al Sur ${ }^{43}$. Durante los pre-

${ }^{41}$ Sobre este documento original del que hay -también- una copia contemporánea y está, además, recogido en el Cartulario, consúltense T. MINGUELLA y ARNEDO, Op. cit., t. I, doc. XXIII, pp. 375-377; H. YABÉN, Op. cit., docs. 20 y 21, pp. 12-13 y M. C. MUÑOZ PÁRRAGA, La catedral..., pp. 34-35.

${ }^{42}$ R. A. FLETCHER, The Episcopate in the Kingdom of León in the Twelfth Century, Oxford, 1978, p. 111. Desafortunadamente no se conservan restos de la utilización de dicho sello.

${ }^{43}$ El 31 de enero de 1145 parece acompañar al monarca en Almazán, desde donde firman un diploma a favor de la Iglesia compostelana, M. RECUERO, Documentos medievales del Reino de Galicia. Alfonso VII..., doc. 108, p. 110 y M. LUCAS, Op. cit., doc. 411, p. 268, este último explica que, aunque el apelativo geográfico del obispo Bernardo aparece mal copiado en los Tumbos A y C de Santiago de Compostela, no parece carecer de legitimidad el texto y la referencia a Bernardo de Agen. parativos de la misma, expectante suum exercitum cerca de Almonacid, el 7 de mayo de 1145 el monarca le cambió al obispo Caracena y Alcubilla por la Sigüenza superior con su castillo, pidiéndole que las dos zonas de la capital de su sede se convirtiesen en una sola villa con un concejo, un juez y un sayón ${ }^{44}$. De nuevo, se acrecentaron el poder y las dimensiones del centro del episcopado que nos ocupa.

El segundo lustro de la década de los años cuarenta de siglo XII se caracterizó por las ausencias continuadas del prelado de su diócesis, lo que nos hace pensar en el papel fundamental que debió desempeñar el cabildo para la buena marcha del obispado y de todo lo que en él se realizase ${ }^{45}$.

Por otra parte, el prelado debía estar inmerso en las directrices marcadas por la iglesia de Roma, aunque la política del reino se inmiscuía en ese campo. De este modo, en el año 1148 asistió a la celebración, en el

${ }^{44}$ Véanse T. MINGUELLA y ARNEDO, Op. cit., t. I, doc. XXV, p. 380, quien extrae la noticia del Cartulario; M. C. MUÑOZ PÁRRAGA, La catedral..., pp. 35 y 36; M. RECUERO, Documentos medievales del Reino de Galicia. Alfonso VII..., doc. 112, p. 115. El diploma, también copiado en el Tumbo compostelano, recoge la confirmación de don Bernardo que aparece como canciller del Emperador, aunque, tal vez, sea un error del copista, como se expone en, M. LUCAS, Op.cit., docs. 324 y 376, pp. 257 y 263.

${ }^{45}$ Por ejemplo, en 1147, cuando se produjo la toma de Almería, don Bernardo acompañó al rey en sus campañas y acabó el año en Toledo. Como capellán del monarca se le encuentra confirmando documentos a favor de la Iglesia de Orense, del monasterio de Antealtares y de Santa María del Sar en los meses de junio, julio y diciembre; en este último se le cita como capellanus imperatoris, véanse, M. RECUERO, Documentos medievales del Reino de Galicia. Alfonso VII..., docs. 114, 115 y 117, pp. 117, 119 ,124 y M. LUCAS, Op. cit., docs. 460, 462 y 467, pp. 274 y 275.

La importancia de los canónigos se rastrea en un documento original, sin fechar, del archivo de la catedral de Sigüenza y en el que Pedro de Carabias, clérigo, se ofrece con todos sus bienes al cabildo y al obispo para ser recibido como canónigo. Por esta carta sabemos que el prior era Wmo [Willelmo] y que los bienes del personaje se compraron con mencales, H. YABÉN, Op. cit., doc. 22 , p. 13. 
mes de febrero, de una reunión conciliar en Palencia, pues Alfonso VII tenía interés en preparar el concilio que el Papa Eugenio III había convocado en Reims para el día 21 de marzo ${ }^{46}$. Las noticias sobre la asistencia de Bernardo de Agen al concilio son confusas, pues únicamente se conservó la mención a un tal B. Segoviensem a través del cual el pontífice envió al Emperador castellano-leonés la rosa de oro, recuerdo del cuarto domingo de cuaresma ${ }^{47}$.

Posteriormente, en 1149, las estancias del prelado en el entorno de la corte fueron numerosas, pero no desatendió sus obligaciones y desvelos hacia el cabildo al que le dio nuevas rentas en Fenares y sus términos; además, ofreció a su Iglesia 12.000 piezas de plata por su alma, la de sus padres, su tío y su hermano ${ }^{48}$. Es muy posible que esa inyec-

${ }^{46}$ G. MARTÍNEZ DÍEZ, Op. cit., p. 331. En el contexto citado, Bernardo de Sigüenza confirma documentos reales en relación con la catedral de León, la Colegiata de S. Isidoro y el monasterio de Sahagún, véanse Ibídem, p. 332; M. LUCAS, Op. cit., docs. 473 y 474, p. 276; E. MARTÍN, Patrimonio cultural de San Isidoro de León. A, serie documental, León, 1994-1995, doc. 44, p. 71; L. GARCÍA CALLES, Doña Sancha hermana del emperador, León-Barcelona, 1972, doc. 24, p. 146 y J. A. FERNÁNDEZ FLÓREZ, Op. cit., t. IV, doc. 1300, p. 215.

${ }^{47}$ El obispo de Segovia en esos momentos era Pedro de Agen (+1149), tío de Bernardo de Sigüenza, ¿es posible que la B. se refiera a Bernardo y esté mal denominado el episcopado?, véase J. P. MIGNE, Patrología Latina, París, 1849-1855, vol. 180, columna 1346. Por otra parte, la relación con el prelado de Segovia le debió facilitar a don Bernardo la compra de unas viñas, una en Celancas y dos en Azuqueca, la transacción se hizo también en febrero de 1148, en Palencia. La noticia procede del Cartulario seguntino, véase T. MINGUELLA y ARNEDO, Op. cit., t. I, doc. XXVII, p. 382 y M. C. MUÑOZ PÁRRAGA, La catedral..., p. 36.

${ }^{48}$ T. MINGUELLA y ARNEDO, Op. cit., t. I, doc. XXVIII, p. 383. Por lo que respecta a la actividad del obispo en el entorno cortesano, en este año 1149, nos deja un halo claro en la documentación. Desde una donación de la infanta doña Sancha, al prelado y su Iglesia, de medio molino, a su presencia en León, el día 6 de marzo, para asistir a la consagración de San Isidoro de León, véanse T. MINGUELLA y ARNEDO, Op. cit., t. I, doc. XXVI, p. 381, H. YABÉN, Op. cit., doc. 23, p. 13, quien fechó la donación del molino en 1149, y comentó su copia en doc. 27, p. 14; E. MARTÍN, "Colección documental de ción de moneda pudiese servir para el pago de obras en la catedral.

Del año 1150, un momento en el que se debían estar preparando cambios para don Bernardo, se conservan noticias referidas a nuevas donaciones y medidas de protección del monarca a la Iglesia de Sigüenza. Así, les dio la heredad de Congosto, cerca del Tajo, y unas salinas que hay sobre ese lugar con una presa para molinos. Por otra parte, eximió a los clérigos seguntinos de pechar o prestar servicios a otro que no fuese el obispo ${ }^{49}$. El resto de documentos lo relacionan premonitoriamente con la Iglesia compostelana ${ }^{50}$.

Además, el primero de septiembre de 1150, el Papa Eugenio III firmó una bula que dirigió al prior Pedro de Sigüenza y sus canónigos, donde confirmaba las donaciones hechas por el obispo Bernardo. También insistía el pontífice en que no se aceptase como canónigo a nadie que no hiciera vida regular, según la regla de san Agustín. Por este diploma conocemos los nombres de otros

la infanta Doña Sancha (1118-1159). Estudio crítico", en León y su Historia. Miscelánea Histórica, VIII, León, 2003, doc. 49, p. 289; L. GARCÍA CALLES, Op. cit., doc. 29, p. 153; A. de FEDERICO FERNÁNDEZ, "Catálogo descriptivo...", doc. 16, p. 11 y M. C. MUÑOZ PÁRRAGA, La catedral..., p. 36: Para San Isidoro, véase E. MARTÍN y V. GARCÍA LOBO, "La epigrafía medieval en España. Por una tipología de las inscripciones", en VIII Jornadas científicas sobre documentación de la Hispania medieval, Madrid, 2009, pp. 185-213, especialmente, p. 196. Además, confirma otro documento del infante Sancho a Santa María de Nájera, de 27 de febrero, J. GONZÁLEZ, El reino de Castilla en la época de Alfonso VIII, 3 vols., Madrid, 1960, t. II, doc. 3, p. 12, y, en el último trimestre del año, firma documentos del monarca realizados en Toledo, a favor de la Iglesia de Osma y del concejo de Atienza, por la ayuda y dinero que le dieron por algunos castillos que están en Fenares, J. LOPERRÁEZ CORVALÁN, Op. cit., doc. XX, p. 25 y T. MINGUELLA y ARNEDO, Op. cit., t. I, doc. XXIX, p. 383.

49 T. MINGUELLA y ARNEDO, Op. cit., t. I, docs. XXX-XXXI, pp. 385-386; H. YABÉN, Op. cit., doc. 24, p. 13; M. LUCAS, Op. cit., docs. 533, 535, p. 283; A. de FEDERICO FERNÁNDEZ, "Catálogo descriptivo...", doc. 17, p. 11; M. RECUERO, Alfonso VII..., p. 229.

${ }^{50}$ M. RECUERO, Documentos medievales del Reino de Galicia. Alfonso VII..., doc. 130, p. 136 y M. LUCAS, Op. cit., doc. 532, p. 283. 
miembros del cabildo, Guillelmus archidiácono, Vicentius y otro Guillelmus, archipresbíteros $^{51}$.

Por último, en el mes de octubre, en Toledo, el obispo Bernardo y el arzobispo Raimundo intercambiaron unas casas en esa misma ciudad ${ }^{52}$.

Para terminar la estancia del obispo en su diócesis, podemos mencionar otros dos diplomas de 1151. En uno confirmó la donación del rey al monasterio gallego de san Miguel de Cans, y en el otro dio a sus canónigos una casa en Sigüenza ${ }^{53}$.

Los documentos aludidos de los años 1150 y 1151 parecen traslucir el interés del prelado en dejar los asuntos de la diócesis bien asentados, las posesiones del cabildo aseguradas y las directrices de la vida comunitaria cimentadas.

Don Bernardo, entre 1151 y 1152, año de su fallecimiento, llegó a ser arzobispo de Santiago de Compostela, donde fue enterrado en el monasterio de Antealtares ${ }^{54}$. El Papa Anastasio IV, en una bula expedida en Letrán el 22 de julio de 1153, donde confirmó las posesiones y privilegios del monasterio de Antealtares y, en especial, el convenio firmado con el arzobispo de Santiago, alude a este como desaparecido, a bone memorie Bernaldo ${ }^{55}$.

${ }^{51} \mathrm{El}$ documento es un original, véase T. MINGUELLA y ARNEDO, Op. cit., t. I, doc. XXXII, p. 387 y M. C. MUÑOZ PÁRRAGA, La catedral..., p. 37.

${ }^{52}$ T. MINGUELLA y ARNEDO, Op. cit., t. I, doc. XXXIII, p. 388; H. YABÉN, Op. cit., doc. 25, p. 13 y M. C. MUÑOZ PÁRRAGA, La catedral..., p. 37, esta última investigadora fecha el documento en 1151.

${ }^{53}$ M. RECUERO, Documentos medievales del Reino de Galicia. Alfonso VII..., doc. 136, p. 143 y T. MINGUELLA y ARNEDO, Op. cit., t. I, doc. XXXIV, p. 389.

${ }^{54}$ R. A. FLETCHER, Op. cit., pp. 77-78 e Historia de las diócesis españolas, t. 14, coordinado por J. García Oro, Madrid, 2002, pp. 54 y 521.

${ }^{55}$ A. LÓPEZ FERREIRO, Op. cit., t. IV, pp. 248-253 y apéndices, pp. 57-59, donde incluye las opiniones publicadas por Jiménez de Rada y el padre Yepes; M. T. GONZÁLEZ BALASCH, Tumbo B de la catedral de Santiago. Estudio y Edición, Santiago de Compostela, 2004, pp. 628-629, especialmente, 628 .
Sus restos fueron trasladados, posteriormente, a Sigüenza y puede ser que, en principio, se colocasen en la capilla de San Agustín, en el brazo norte del crucero. Como este ámbito desapareció cuando se hizo la obra de la girola, a esta pasarían después en un monumento funerario, de finales del siglo $\mathrm{XV}$, en el que se conserva un epitafio, poco exacto, del siglo $\mathrm{XVI}^{56}$.

Para concluir este apartado, debemos tener en cuenta la potencialidad de la diócesis de Sigüenza respecto al resto de los episcopados castellano-leoneses, con el fin de aquilatar los medios de los que disponía a la hora de realizar una obra catedralicia importante. Parece ser que, desde la última década del reinado de Alfonso VII (†1157), según se ha estudiado, ocupaba Sigüenza un puesto de tercera fila entre las diócesis españolas, y, con datos de 1262 , se la situaba en una medianía, a la altura de Cuenca o Segovia, momento en el que el Papa le pide, como a las otras dos, 250 maravedíes para apoyar al Imperio Latino de Oriente. Esta situación parece cambiar poco, pues, al finalizar el siglo XIII, se la pone a la altura de Calahorra, Plasencia y León, en un cuarto nivel de renta, de los cinco analizados, en relación con los libros de cuentas de Sancho IV ${ }^{57}$.

\footnotetext{
${ }^{56}$ En la inscripción funeraria se dice que el prelado reedificó y bendijo esta iglesia en el día de san Esteban del año 1123. No sabemos a qué edificio se refiere ni en qué lugar estaría emplazado, pero se advierte la rapidez de sus actuaciones, si es que podemos tener en cuenta estos datos, véanse T. MINGUELLA y ARNEDO, Op. cit., t. I, pp. 89-92; F. PECES RATA, Catedral de Sigüenza. Fortis seguntina, Barcelona, 2007, pp. 52-53 y M. C. MUÑOZ PÁRRAGA, La catedral..., pp. 37-40. Don Bernardo debió de ser enterrado al lado de su madre en la catedral, ya que actualmente en la zona inferior de su monumento funerario se conservan dos pequeñas piezas pétreas, con epígrafes en letra gótica, que aluden a ambos. Además, el epitafio sirvió a algunos investigadores para indicar los inicios del edificio, añadiendo a ese dato otros, de desconocida procedencia, que situaban el templo en el mismo paraje donde estuvo la iglesia antigua, antes de la invasión musulmana, véase A. PONZ, Viaje de España, Madrid, 1772-1794, reedición de Madrid, 1988, vol. III, tomo XIII, p. 789.

${ }^{57}$ C. REGLERO, "Reyes y obispos en los reinos de León y Castilla (c. 1050 - c. 1200): oración, servicio y me-
} 
Este panorama pudo redondearse con la documentación pontificia de la decimotercera centuria; en ella, seis bulas parecen reflejar ciertas dificultades de la diócesis de Sigüenza para pagar deudas, terminar las obras catedralicias e incluso atraer fieles. El Papa les concedió tercias para la fábrica, prometió interceder ante el rey para que cediese las suyas, incluso para luminarias u ornamentos, $\mathrm{y}$, además, insistió en dar indulgencias a los que visitasen la sede en determinadas festividades ${ }^{58}$.

El complejo entramado histórico, que aún se puede documentar, de los inicios pleno medievales de la diócesis seguntina, conduce al investigador a pensar, razonablemente, que las condiciones económicas y organizativas que se dieron allí, durante los años treinta y cuarenta del siglo XII, son más que suficientes para poner en marcha la realización del conjunto edilicio central del episcopado.

Las obras del templo, en 1156, tenían que continuar con el cierre superior de los

moria", en M. D. TEIJEIRA, M. V. HERRÁEZ y M. C. COSMEN (eds.), Reyes y prelados. La creación artística en los reinos de León y Castilla (1050-1500), Madrid, 2014, pp. 45-66, especialmente pp. 51-52 e ÍDEM, “El obispado de Osma...", pp. 218-222.

${ }^{58}$ Honorio III, en 1220, se hace eco de las deudas de Sigüenza frente a Pamplona y en 1226 le posibilita al obispo don Lope (1221-1237) que pueda pagar lo que debe con rentas de los beneficiados no residentes, pero, además, le permite el uso de las tercias, durante tres años, para pagos de la construcción de la catedral. Posteriormente, Inocencio IV, en 1251, concede indulgencias a los que visiten la sede en determinadas festividades y, en 1252, se compromete a solicitar a Alfonso X las tercias que le cedió, pues la Iglesia de Sigüenza las necesitaba para las fábricas, las luminarias y los ornamentos. Por último, Nicolás IV, en 1289, vuelve a otorgar 40 días de indulgencias a los fieles que visiten la catedral seguntina en las festividades de la Natividad, la Purificación de María, la Anunciación, la Asunción y el día de san Pedro, véase D. MANSILLA, La documentación pontificia de Honorio III (1216-1227), Roma, 1965, doc. 60, p. 465; E. LAMBERT, Op. cit., p. 295 y S. DOMÍNGUEZ SÁNCHEZ, Documentos pontificios relativos al mecenazgo papal del primer arte gótico hispano (1198-1314), León, 2015 , docs. $19,28,39,40,168,173$ y 297 , pp. $58,62,66$, 126,128 y 189 .

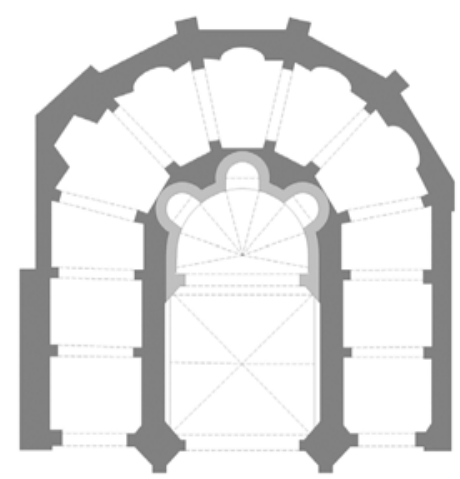

- Fig. 5. Catedral de Sigüenza. Cabecera románica con tres absidiolas, sobre planta actual. Dibujo de Ramón Rodríguez Pallarés.

ábsides y el remate de la construcción de la cruz de toda la iglesia, pero esta noticia parece traslucir que el diseño y cimentación del edificio estaban ya realizados.

\section{DISEÑO DEL PRIMER PRESBITERIO}

La revisión hecha in situ del alzado inferior del ábside mayor de la catedral de Sigüenza, remite a una planta semicircular, de $10 \mathrm{~m}$ de diámetro, en la que se construyeron tres exedras, una en el centro de su eje, y otras dos, emplazadas radialmente, una a cada lado y separadas por dos metros de distancia de la central (Fig. 5).

En cuanto al paramento interno de este testero, una fotografía antigua del mismo, sin el retablo, deja ver con claridad, en el primer piso, las arquerías de enmarque superior de dichos nichos. Los dos de los extremos aparecen totalmente tapiados, por lo que se pensó que eran arcuaciones ciegas decorativas, sin más desarrollo, pero, el central denota las obras del camarín (Fig. 6) ${ }^{59}$.

Las tres absidiolas están rematadas por un arco, de 2,40 m de luz, que se moldura con un gran bocel de $25 \mathrm{~cm}$ de diámetro, trasdosado por una media caña, más estre-

${ }^{59}$ La fotografía fue realizada por el arquitecto A. Labrada que se hizo cargo de la restauración del edificio tras los destrozos de la guerra civil. La imagen se conserva en la fototeca del Instituto de Patrimonio Cultural de España y ha sido múltiples veces reproducida como en AA. VV., La catedral...la puesta en..., p. 39. 


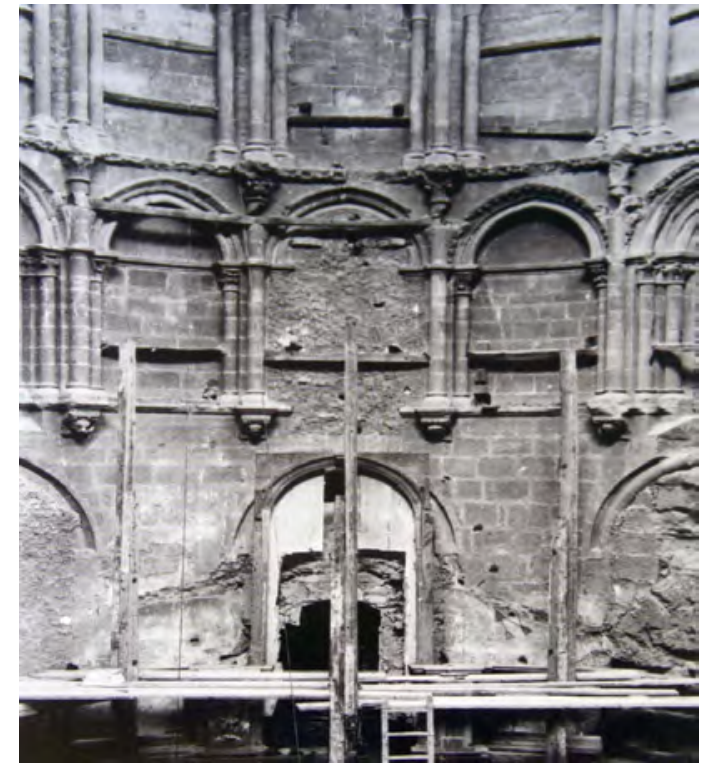

- Fig. 6. Catedral de Sigüenza. Presbiterio, sin retablo, durante la reconstrucción, tras los destrozos de la Guerra civil (fotografía de A. Labrada) en AA.VV. La catedral de Sigüenza..., p. 39.

cha, de $12 \mathrm{~cm}$ de diámetro (Fig. 1). Ambos elementos están rematados, en su base, por formas semicirculares planas (Fig. 7).

Dichas arquerías, idénticas en los tres casos, colocan sus salmeres a casi cinco metros de altura, exactamente a $4,85 \mathrm{~m}$ del suelo actual, En el interior del nicho, eje de la composición, pudimos precisar un tramo recto de $92 \mathrm{~cm}$ de profundidad al que se le añade el semicírculo engendrado por la luz de 2,40 m, es decir, con un radio de 1,20 m Por lo tanto, cada absidiola debe tener una profundidad aproximada de 2,12 m.

El muro de cierre, de esta capilla en exedra, presenta en su eje un vano, del que se pudo ver el remate en arco de medio punto que fue realizado con dovelas planas (Fig. 8). La ventana está situada a considerable altura por lo que es posible suponer la existencia de otro orden de vanos inferior, para la iluminación directa del ara.

El paramento oriental curvo del gran presbiterio sería soporte de una bóveda que cerraría la cabecera. No obstante, los cambios sucesivos llevados a cabo en el alzado del templo hicieron variar la planificación original, tal como se advierte en la fotografía

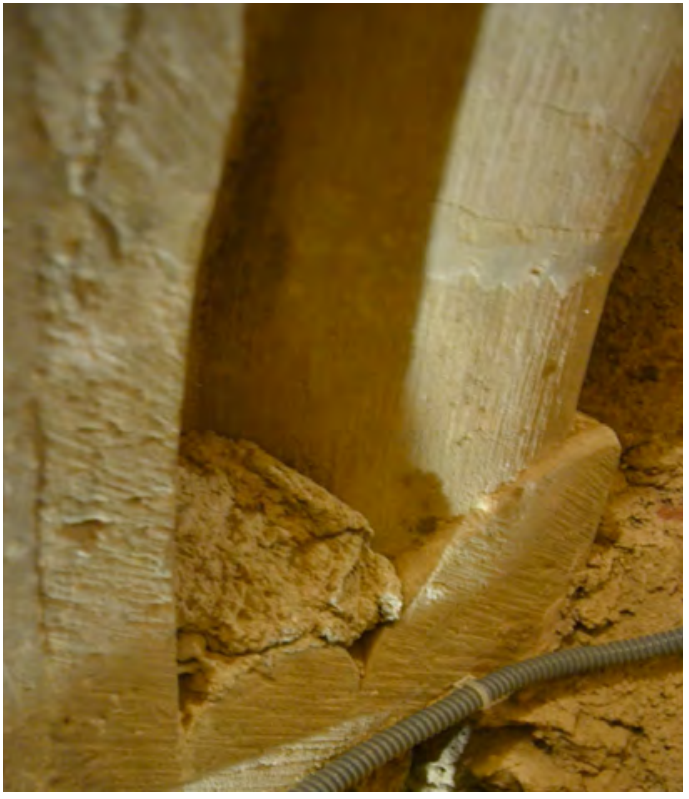

- Fig. 7. Catedral de Sigüenza. Remates inferiores de las molduras que enmarcan las absidiolas. Foto de la autora.

sin retablo y en la del tramo más occidental del presbiterio, donde otros tres niveles en altura indican esas campañas posteriores, con sus características formales específicas para cada una (Figs. 6 y 9) ${ }^{60}$. Es interesante constatar que, sobre los arcos de medio punto del remate superior de las absidiolas, se

${ }^{60}$ La doctora Muñoz ya explicó, con todo detalle, estas fases constructivas, véase M. C. MUÑOZ PÁRRAGA, La catedral..., pp. 92-93, 102-109 y 188-193. Por otra parte, en un trabajo más reciente se estudiaron, empleando técnicas de medición láser, las bóvedas del presbiterio y del transepto catedralicio en relación con las del refectorio del monasterio de Santa María de Huerta, relaciones a las que había llegado la profesora Muñoz Párraga. Los resultados de la investigación diferencian a los maestros de ambos edificios, en cuanto a la forma de tallar y colocar las piezas que componen esas cubiertas. Huerta, más compleja, se pudo realizar entre 1223 y 1225; Sigüenza, en cambio, con soluciones más sencillas, aunque estructuralmente peores, pudo ser obra de la segunda mitad del siglo XIII, realizada por un aprendiz del monasterio citado, véase J.C. PALACIOS GONZALO y R. MAIRA VIDAL, "Nuevas tecnologías de medición al servicio del patrimonio: Sigüenza y Santa María de Huerta", en S. MORO ALONSO-MUÑOYERRO y A. RUEDO MÁRQUEZ DE PLATA (eds.), Actas del Congreso Internacional sobre Documentación, Conservación y Reutilización del Patrimonio Arquitectónico, Madrid, 2013, vol. I, pp. 555-562. 


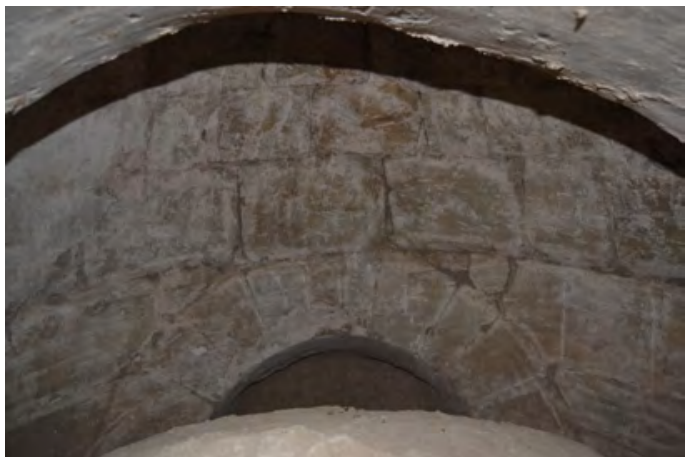

- Fig. 8. Catedral de Sigüenza. Interior del paramento de cierre de la absidiola central con un vano. Foto de la autora.

colocó un piso de arquerías ciegas y vanos, hoy tapiados, donde los arcos de enmarque son ya apuntados y presentan chambranas y capiteles con decoración vegetal. Este nivel se apoya en una imposta moldurada bajo la que se hicieron ménsulas decoradas con cabezas como apeo de pequeñas columnas, ubicadas entre los arcos, que nos obligan a pensar en la recepción de posibles nervios (Fig. 6).

Tal vez estas obras se hicieron a partir de 1156, cuando el obispo Pedro de Leucata, como hemos citado, hablaba de la terminación de las cabezas de los altares, y, consecuentemente, se introdujeron formas decorativas y estructurales más acordes con los años centrales del siglo XII.

\section{FILIACIÓN DEL MODELO ELEGIDO}

El descubrimiento de los restos citados en la cabecera del templo mayor seguntino nos ha llevado a intentar rastrear el modelo dentro del occidente románico europeo. Sabemos que esta tipología no es común en el Románico de la Península Ibérica, pero cierto parecido, aunque más sencillo, se puede hallar en la Seo de Urgell. En este caso solamente una exedra se abre en el eje de la capilla central y no sobresale en planta al exterior, pues queda inmersa en el muro perimetral ${ }^{61}$. Una solución parecida está presente en

${ }^{61}$ La catedral de Urgel, dedicada también a Santa María, se rehízo desde principios del siglo XII, su promotor fue Saint-Ot y la obra se relacionó con maestros

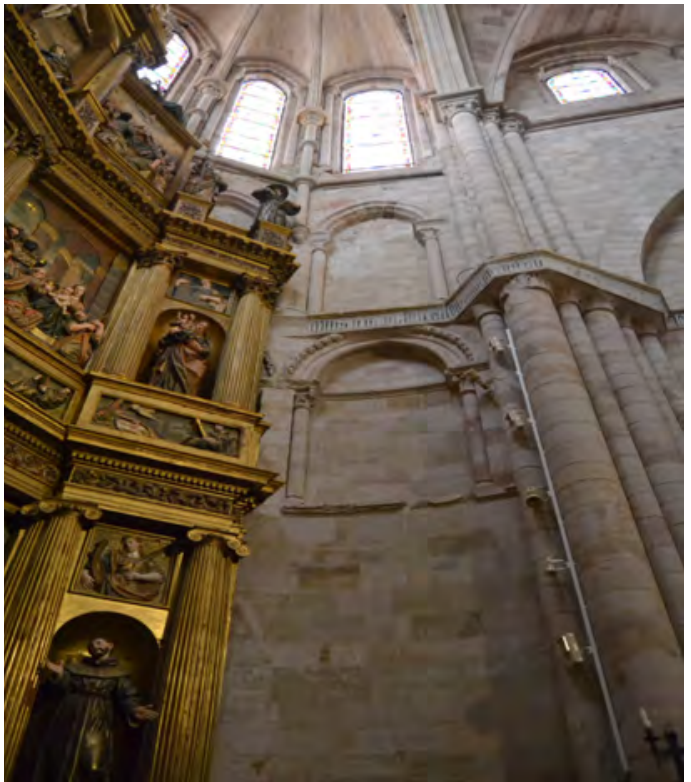

- Fig. 9. Catedral de Sigüenza. Muro interior del presbiterio y sus niveles constructivos. Foto de la autora.

el ábside principal de san Pedro de la Rúa, en Estella. Pero, en esta ocasión, son tres absidiolas las que se disponen radialmente en el muro del testero, como en el caso de Sigüenza ${ }^{62}$.

italianos o alemanes, pero actualmente se piensa que sus características son más próximas a los templos de los monasterios de Ripoll o Cuixà, véanse C. BARAUT, "Els documents dels anys 1101-1150, de 1'Arxiu Capitular de la Seu d 'Urgell", Urgellia, 9, 1988-1989, pp. 7-570; J. A. ADELL y otros, La catedral de La Seu de Urgel, Manresa, 2000; G. BOTO y M. SUREDA, “Les cathédrales romanes catalanes. Programmes, liturgie, architecture", Les Cahiers de Saint-Michel de Cuxà, XLIV, 2013, pp. 7589 , especialmente pp. 82-84 y figura 7 de la p. 83. En otros edificios catalanes existen soluciones parecidas, como en los casos de San Miguel de Ponts y San Ponce de Corberá, como ya han explicitado las doctoras Muñoz Párraga y López de Guereño al estudiar San Pedro de la Rúa en Estella (Navarra), véase, M. C. MUÑOZ PÁRRAGA y M. T. LÓPEZ DE GUEREÑO, “Las fábricas medievales de San Pedro de la Rúa en Estella (Navarra): la complejidad de un largo proceso constructivo", De Arte, 11, 2012, p. 32, nota 18.

${ }^{62}$ El ejemplo navarro ha sido muy estudiado desde las campañas de restauración y excavación que ha sufrido el edificio en fechas recientes y la filiación del modelo se ha llevado al Sur de Francia. La cronología que se ha adjudicado -inicialmente- a esta campaña del ábside central, con absidiolas, es del último cuarto del siglo XII, véase M. C. MUÑOZ PÁRRAGA y M. T. 
Otro ejemplo parecido, aunque de una complejidad mayor, se encuentra en la iglesia de San Pedro de Ferreira, al Noreste de Oporto, en Portugal. En este caso, el edificio, construido posiblemente en el último cuarto del siglo XII, presenta una cabecera de planta semicircular con amplio tramo recto a la que se abren cinco capillas, las tres centrales tienen planta semicircular y las de los extremos poligonal. Todo este complejo festoneado interno tampoco sobresale al exterior, está embebido en el paramento curvo del ábside ${ }^{63}$.

Como los casos hispanos eran poco frecuentes, la búsqueda continuó hasta conducirnos a modelos que se hallan en lugares relacionados con los primeros comitentes del templo. Así, hemos podido comprobar que en Aquitania, y más concretamente en las zonas de Gascogne y del Agenais, esta tipología de cabecera no fue infrecuente ${ }^{64}$. Tal es el caso del templo del antiguo priorato de San Caprasio de Agen, erigido desde fines del siglo XI, y cuya cabecera y transepto pudieron llevarse a efecto a principios de la duodécima centuria. El edificio, que se convirtió en catedral de la diócesis en los inicios del siglo XIX, conserva un gran ábside semicircular, al que se abren tres exedras poco profundas, $\mathrm{y}$ un crucero, con una absidiola en cada brazo (Fig. 10) ${ }^{65}$. Lo interesante es saber que este

LÓPEZ DE GUEREÑO, Op. cit., p. 46. En otro estudio pormenorizado del conjunto se han podido adelantar un poco dichas fechas, hacia el segundo tercio del siglo XII, argumentando, detalladamente, para ello, particularidades arquitectónicas y escultóricas, véase J. MARTÍNEZ DE AGUIRRE, "Arquitectura Medieval", en M. R. LAZCANO MARTÍNEZ DE MORATÍN (coord..), San Pedro de la Rúa de Estella, Pamplona, 2012, pp. 53101, especialmente pp. 77-79.

${ }^{63}$ G. N. GRAF y A. N. DE GUSMAO, Europa Románica. Portugal/2, Madrid, 1988, pp. 75-87 y láminas 116 a 119 en pp. 46 a 48.

${ }^{64}$ Este mismo camino lo han indicado otros investigadores, como hemos dicho, en relación con san Pedro de la Rúa de Estella.

${ }^{65}$ J. R. MARBOUTIN, "La cathédrale d'Agen", Revue de l'Agenais, t. 58, 1931, pp. 121-136 y pp. 209219; R. CROZET, "Saint- Caprais d'Agen", Congrès Archéologique de France, 1969, Agenais-Paris, 1969,

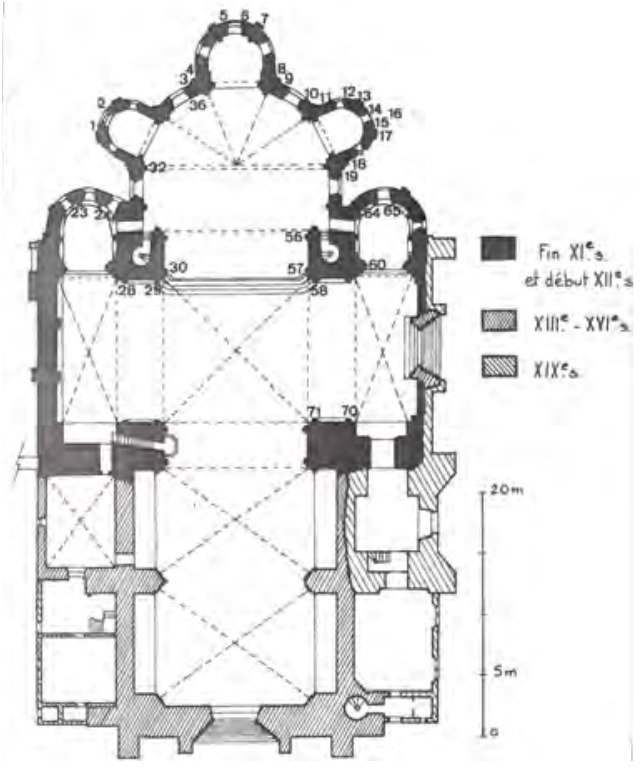

- Fig. 10. San Caprasio de Agen. Planta del templo en J. CABANOT, Les debuts de la sculpture romane dans le sud-ouest de la France, Paris, 1987, p. 187.

diseño estuvo antes presente en el templo del Monasterio de San Orencio de la ciudad gascona de Auch, situada a unos $70 \mathrm{~km}$ al sur de Agen, y cuya iglesia fue consagrada en 1075. De dicha institución hoy se conservan escasos restos medievales, pero, en el siglo XIX, los estudios histórico-artísticos y arqueológicos condujeron a recomponer sus estructuras arquitectónicas (Fig. 11) ${ }^{66}$.

Por otra parte, el mismo tipo de presbiterio se realizó en otros edificios situados al norte de la zona citada. Nos referimos a la primera cabecera de la catedral de San Esteban de Cahors, datada posiblemente antes de 1119, momento de su consagración, y a la de la abadía de Santa María de Souillac, ambas en el Quercy, pero en esta última los

pp. 82-97; P. DUBOURG-NOVES, Guyenne Romane, "Zodiaque", la nuit des temps, Yonne, 1969, pp. 254256; J. CABANOT, Les debuts de la sculpture romane dans le sud-ouest de la France, Paris, 1987, pp. 125-126 y 186189.

${ }^{66}$ F. CANÉTO, "Prieuré de Saint-Orens d'Auch", Revue de Gascogne, t. 8, 1867, pp. 1-377, especialmente pp. 216-219. En este texto se abocetó la planta del templo que ha tenido que ser redibujada para esta publicación. Agradezco a Ramón Rodríguez Pallarés su excelente trabajo. 


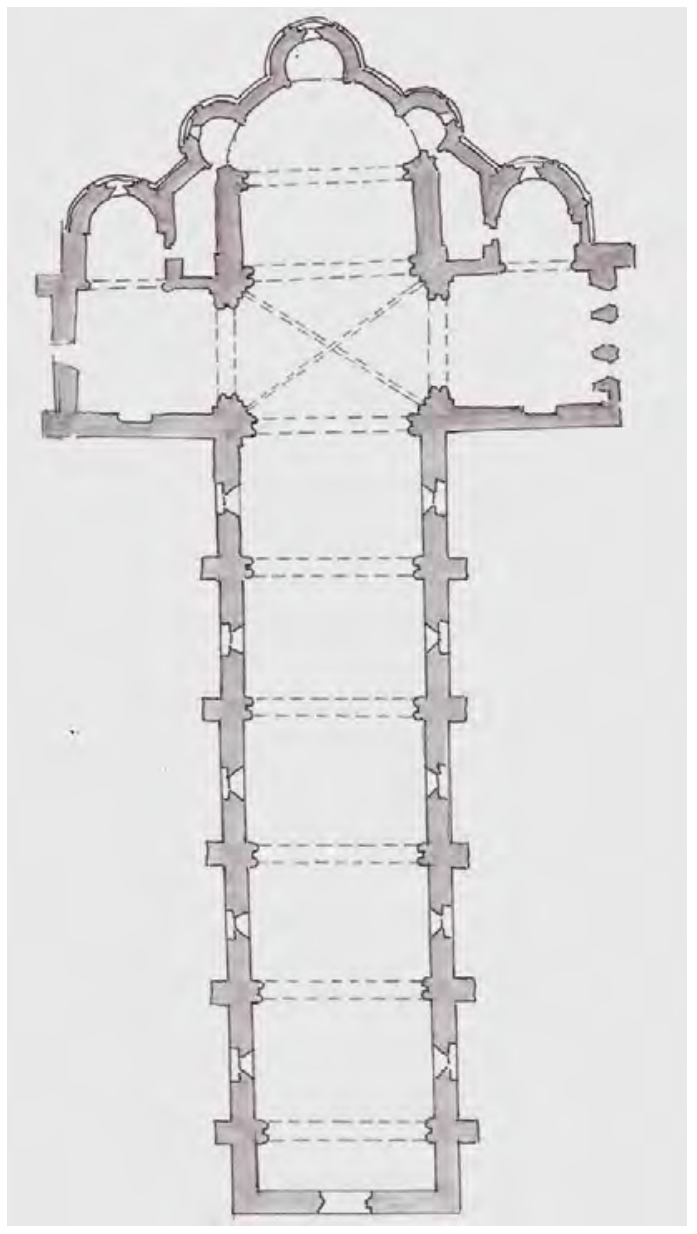

- Fig. 11. San Orencio de Auch. Planta del templo según F. CANETO, "Prieuré de Saint-Orens d' Auch", Revue de Gascogne, t.8, 1867, p. 311.

testeros de las absidiolas son poligonales y su construcción se hizo antes de 1128, siguiendo el modelo de Cahors ${ }^{67}$.

El ábside único, al que se abren exedras poco desarrolladas, siguió su expansión hacia el Limousin donde está presente en la abadía de Solignac y en el templo de San Pe-

${ }^{67}$ M. VIDAL, J. MAURY y J. PORCHER, Quercy Roman, "Zodiaque", la nuit des temps, Yonne, 1969, pp. 191-232 y 249-287, especialmente pp. 197, 200, 254 y 258; M. DURLIAT, “La cathédrale de Saint-Étienne de Cahors. Architecture et sculpture", Dixième Colloque International de la Société Française d'Archéologie (Cahors, 13-14 Octobre 1978), Bulletin Monumental, t. 137IV, 1979, pp. 285-340. En este trabajo el doctor Durliat realizó un rastreo intensivo del modelo de planta de la catedral de Cahors, que también lo condujo a San Orencio de Auch, y publicó las plantas de los ejemplos más significativos. dro de Vigeois, lugares emplazados al sur de Limoges y datados en el siglo XII ${ }^{68}$.

Junto a las características citadas, también debemos señalar que casi todos estos edificios aparecen dotados de transepto, norma de la que únicamente tenemos que excluir a la catedral de Cahors, y en el muro oriental del crucero se abren dos absidiolas, una en cada brazo ${ }^{69}$. Por otra parte, para el cuerpo del edificio lo común, en el grupo de templos citado, es la existencia de una sola nave que puede estar cubierta con cúpulas, tal como ocurre en Cahors, Souillac e incluso, como se cree que se cerró, originariamente, San Caprasio de Agen; pero no fue así en San Orencio de Auch, que tuvo una bóveda de cañón sobre fajones, tal y como describen los textos conservados de la abadía que recopiló en el siglo XIX François Canéto ${ }^{70}$.

Por lo tanto, el modelo básico de iglesia, a tener en cuenta, se componía de un presbiterio semicircular con tres absidiolas radiales, de profundidad comedida, abiertas en el muro en exedra, y un crucero con otras dos capillas, una en cada brazo. Todos estos espacios festoneaban con sus testeros curvos el exterior del edificio.

En el caso de la catedral de Sigüenza tenemos el presbiterio semicircular con las tres capillas poco profundas en disposición radial, pero dado que las obras de la girola, realizadas en los últimos años del siglo XVI, disimularon estos espacios y los dejaron embebidos en un ancho muro -que llama poderosamente la atención en los planos de la iglesia que se han publicado- no podemos saber, de momento, cómo se manifestarían las exedras al exterior ${ }^{71}$.

Por lo que respecta a las medidas de la planta seguntina debemos insistir en que

${ }^{68}$ M. DURLIAT, Op. cit., p. 298.

${ }^{69} \mathrm{Ibídem,} \mathrm{pp.} \mathrm{288,} \mathrm{301y} 307$.

${ }^{70}$ F. CANÉTO, Op. cit., p. 215 y J. CABANOT, Op. cit., p. 188.

${ }^{71}$ Véanse los planos publicados por la doctora Muñoz Párraga, La catedral..., anexos; y los de AA.VV., La catedral... La puesta en..., p. 27. 
son más reducidas que las que se desarrollan en los ejemplos franceses citados, donde, en ningún caso, el diámetro del ábside principal es menor a $13 \mathrm{~m}$. En San Caprasio de Agen alcanza los 15,50 m y su absidiola central tiene $4,5 \mathrm{~m}$ de diámetro y las laterales 3,2 m. En el caso de San Orencio de Auch el ancho del presbiterio era de $14,50 \mathrm{~m}$.

En Sigüenza se realizó un presbiterio de $10 \mathrm{~m}$ de diámetro y proporcionalmente, como era de esperar, la absidiola central tiene 2,40 m de ancho, medidas que parecen repetir las exedras laterales, según su arco superior de enmarque.

En cuanto a las capillas abiertas en los muros orientales del crucero, se podría, al menos, plantear alguna duda sobre la existencia de dos para cada brazo.

El que existan cinco altares principales, citados por el obispo don Rodrigo (11921221) en la creación de la sacristanía, que es aprobada por el Papa en 1197, no es razón suficiente para explicar el desarrollo de la cabecera con cinco ábsides en batería.

Además, tal y como aparece en la documentación del siglo XVI, se habría instalado la capilla de San Agustín en el lado del evangelio y la de San Pedro Apóstol en el de la epístola ${ }^{72}$.

Por otra parte, es un hecho incontestable que el altar dedicado a Santo Tomás de Canterbury no podía estar en el proyecto inicial de la cabecera, pues el arzobispo no fue canonizado hasta el año 1173. Por lo tanto, incluso las obras que el prelado Pedro de Leucata (1152-1156) quería que se terminasen, en cabecera y transepto, no incluían este ámbito $^{73}$.

\footnotetext{
${ }^{72}$ M. C. MUÑOZ PÁRRAGA, La catedral..., p., 92.

${ }^{73}$ Ibídem, p., 75. Tomás de Canterbury fue canonizado por el Papa Alejandro III el 21 de febrero de 1173. La importancia de su figura en relación con los Reinos hispanos y el Arte medieval se puede revisar en, AA.VV., Tomás Becket y la Península Ibérica, León, 2013. En este trabajo se explica la relación y desencuentro de su persona con el poder civil en busca de la independencia de la Iglesia, así como su cercanía a los canónigos re-
}

Pudo tratarse de un obispo posterior, don Joscelino Adelida (1168-1178), quien llevase a cabo la instalación de la citada advocación en Sigüenza, como lo hizo su antecesor don Cerebruno (1156-1166) cuando pasó a ocupar la cátedra toledana y en la catedral primada dedicó una capilla al clérigo normando $^{74}$.

Si estudiamos detenidamente el plano de la cabecera de la catedral seguntina (Fig. 3), las medidas del crucero admiten de forma poco clara la colocación de las dos capillas a cada lado de los brazos. Además, las excavaciones que se han hecho en el flanco meridional del templo han sacado a la luz estructuras, nunca concluidas, en relación al diseño del brazo sur y sus torres de enmarque, que no harían más que limitar su amplitud definitiva ${ }^{75}$. De todos modos, es difícil aventurar más soluciones sin una prospección global, ya que el edificio sufrió cambios de planes en este transepto que son visibles en sus muros altos y que pudieron enmascarar otro proyecto anterior ${ }^{76}$.

\section{RELACIONES INTERNACIONALES: LOS HOMBRES Y LAS RELIQUIAS}

Las conexiones que nos conducen a Agen y Auch pueden ampliarse a otros lugares, siempre dentro de la misma Aquitania, que nos permitirán, a su vez, encontrar vínculos con el Reino de León y Castilla desde el último tercio del siglo XI. Por ejemplo, de la Colegial de San Caprasio dependía el se-

gulares, con los que se educó en Merton; por ello, no es extraño que obispos y canónicas catedralicias impulsaran decididamente su santificada figura, véase AA.VV., Tomás Becket y..., pp. 228-230 y para Sigüenza, p. 69.

${ }^{74}$ M. C. MUÑOZ PÁRRAGA, La catedral..., p., 75.

${ }^{75}$ Los informes arqueológicos se pueden leer en el AIPCE, PD 264/4, pp. 9, 13 y 48, donde se recogen también las plantas de los muros y restos destacables. El asunto es compendiado también en, AA. VV., La catedral...La puesta en..., pp. 149-160, especialmente en $\mathrm{p}$. 152 y planos de la p. 157.

${ }^{76}$ M. C. MUÑOZ PÁRRAGA, La catedral..., véanse, para el transepto, las pp. 110-114, 193-199 y los planos de los anexos. 
ñorío de La Sauvetat de Savères, feudo que se consideró una de las joyas de la mesa del capítulo agenense, y que, desde 1203, compartieron los canónigos con el conde de Toulouse y, posteriormente, con el rey de Francia, como heredero de aquel condado. La Sauvetat era el lugar de procedencia de Bernardo de Sédirac, abad de Sahagún en el primer lustro de los años ochenta del siglo $\mathrm{XI}, \mathrm{y}$, posteriormente, arzobispo de Toledo hasta su muerte en 1125. Este personaje que, antes de salir de su país, había sido nombrado prior de San Orencio de Auch en 1078, estaba ligado a los círculos benedictinos $\mathrm{y}$, a consecuencia de su mediación, vinieron a la península una serie de clérigos francos destinados a regir varias de las diócesis hispanas. Entre ellos se encontraba Bernardo de Agen, quien llegaría a ser obispo de Sigüenza en los años 20 del siglo XII ${ }^{77}$.

Otro dato que nos permite anudar con fuerza el centro diocesano seguntino con el sur-oeste de Francia son las reliquias de los

77 Collegiale d'Agen, consultado el 23/7/2014. URL:http://genealogie-en-47.fr/Eglises/Eglises/Eglises_Agen_Collegiale_01.html,; R. JIMÉNEZ DE RADA, Op. cit., pp. 249-250; P. LARROQUE, “Dom Bernard de Sédirac. Né à la Sauvetat (Gers)", Revue de Gascogne, t. 1, 1860, pp. 101-121; F. CANÉTO, Op. cit., especialmente pp. 249, 256, 257-261. M. DEFOURNEAUX, Les français en Espagne aux XIe et XIIe sècles, Paris, 1949, pp. 18-23 y 36; P. MARTÍNEZ TABOADA, “Los obispos aquitanos en los primeros siglos de la reconquista castellana (su relación con la diócesis de Sigüenza)", Anales Seguntinos, vol. I, no 1, 1984, pp. 21-30, especialmente pp. 26-27. Son muchos los estudios que tocan de algún modo la figura del primer obispo seguntino por lo que sólo cito alguno de ellos y remito a la bibliografía de Sigüenza citada en la nota 3. Lo mismo ocurre con el arzobispo Bernardo de Toledo, por lo que solamente cito algunas obras de referencia, P. E. FLÓREZ, España Sagrada, t. VIII, Madrid, 1752, p. 127; J. F. RIVERA RECIO, La Iglesia de Toledo en el siglo XII (1086-1208), Roma 1966 y El arzobispo de Toledo don Bernardo de Cluny (1086-1124), Roma, 1962; B.F. REILLY, Op. cit., pp. 246-247; R. A. FLETCHER, Op. cit., pp. 77-78; C de AYALA, Op.cit., p. 408 y C. REGLERO, "Los obispos y sus sedes en los reinos hispánicos occidentales. Mediados del siglo XI-mediados del siglo XII: tradición visigoda y reforma romana", en XXXII Semana de Estudios Medievales. Estella, 18-22 de julio, 2005. La reforma gregoriana y su proyección en la cristiandad occidental. Siglos XI-XII, Pamplona, 2006, pp. 195-288, especialmente pp. 230-231 y notas 132 y 151. santos Librada y Sacerdote que se comenzaron a venerar en la catedral de Sigüenza. No se conoce el momento en el que estos restos llegaron, pero es muy probable que fuese Bernardo de Agen el que los consiguiese, en la primera mitad del siglo XII, tal vez para emplearlos en la consagración del edificio. No obstante, el éxito fue inmediato, pues muy pronto los obispos de Segovia, Palencia, Oviedo y Toledo, casi todos antiguos compañeros del prelado, le pidieron reliquias de la santa para sus catedrales ${ }^{78}$. El obispo Minguella escribió que desde el siglo XII los santos mencionados fueron patrona y copatrono de la sede seguntina, aunque no se sabe exactamente dónde, al principio, se depositaron sus vestigios ${ }^{79}$. Parece que pudo existir una cripta debajo del altar mayor y cuando en 1250 el Papa Inocencio IV concedió 40 días de indulgencia a los fieles que en la fiesta de la mártir, el 18 de febrero, visitasen el templo, se especificó que la iglesia estaba dedicada a la Virgen María y a

${ }^{78}$ Santa Librada fue una mártir tardo-antigua que desde época carolingia se veneraba en un templo a cuyo alrededor se desarrolló la ciudad de Sainte-Livrade-surLot, en la Guyenne francesa, a unos $30 \mathrm{~km}$ al norte de Agen. En el año 1116, esa iglesia y su comunidad de canónigos pasó a depender de la Chaise-Dieu de Auvernia; con estas premisas desconocemos cómo, cuándo y por qué cedieron parte de sus reliquias más preciadas a don Bernardo.

San Sacerdote (Saint-Sardos), por su parte, fue obispo de Lyon en el siglo VI y sus restos se honran en la catedral de Sarlat-la-Canéda, en el Perigord, excepto el cráneo que fue traído a Sigüenza.

Todos los lugares citados están en Aquitania, a unos $60 \mathrm{~km}$ de distancia entre ellos. Además, varios pequeños asentamientos con la denominación de SaintSardos se ubican en las proximidades de Agen, lo que nos ha hecho pensar en la gran devoción que se le tenía. Véanse, G. de TOURS, Vie des Péres, Paris, 1985, chapitre VIII, consultado el 23/7/2014. URL: http://termacle.org/ bloodwolf/historiens/gregoire y P. DUBOURG-NOVES, Op. cit., p. 259. Para toda la historia de los santos citados en relación con Sigüenza y su devenir histórico y documental, véase A. BISLENGHI, Luces y sombras. Mil años de amor y devoción a Santa Librada, Sigüenza, 2003, en este texto, para el momento inicial que nos ocupa ahora, pp. 21 a 24,50 y 74 .

${ }^{79}$ T. MINGUELLA y ARNEDO, Op. cit., t. I, p. 289 y A. BISLENGHI, Luces y sombras..., p. 99. 
los santos Sacerdote y Librada ${ }^{80}$. Por lo tanto, la relevancia de dichos bienaventurados fue plenamente asumida por el centro de la diócesis y Roma la corroboró.

Si las reliquias de los venerables franceses estuvieron ubicadas en una pequeña estancia subterránea en el entorno del altar mayor, es probable que algún lugar relevante, del presbiterio y transepto primitivos, se reservase a los oficios litúrgicos a ellos dedicados. Pero, como en el documento aludido de 1197 no se citan sus nombres, la situación se complica más y nos imposibilita llegar a conclusiones definitivas. No obstante, es imperativo reseñar que, como aparece más tarde en el Directorio del Coro de Sigüenza, del siglo XVII, las celebraciones que se realizaban, dedicadas a los santos galos, se seguían haciendo con gran solemnidad, aunque en altares diferentes a los originales ${ }^{81}$.

${ }^{80}$ A. BISLENGHI, Luces y sombras..., p. 52. La ubicación de una cripta, tras el altar mayor, también la señaló Pérez-Villamil, M. PÉREZ-VILLAMIL, Op. cit., p. 216.

${ }^{81}$ La situación actual del conjunto monumental dedicado a Santa Librada es muy relevante, ya que tras las obras en el templo, durante el siglo XVI, ocupó gran parte del muro septentrional del transepto. Los restos de San Sacerdote se colocaron, por su parte, en uno de los espacios creados en torno a la nueva girola. Véase F. PECES RATA, Op. cit., pp. 41-44 y 58. Sobre el traslado de los bienaventurados pueden revisarse, para San Sacerdote, T. MINGUELLA y ARNEDO, Op. cit., t. I, p. 290 y para Santa Librada, J. A. MARTíNEZ GÓMEZGORDO, "Las reliquias itinerantes de Santa Librada, Virgen y Mártir", Ábside, no 5, 1988, pp. 17-21 y A. BISLENGHI, Luces y sombras..., pp. 54-61. En el Archivo de la Catedral de Sigüenza puede consultarse el Directorio del coro en 4 volúmenes, de 1610 y 1611, con añadidos de 1823. En el tomo II, fol. 46v. se habla de la fiesta de Santa Librada y en el fol. 79v. de la de San Sacerdote. Pero, además, en el tomo IV, fols. 3r., 178v., 542r. y $543 v$. se incide en los oficios en los que se incluyen los altares de los santos aludidos. Por otra parte, en los Estatutos y reglas de puntar, Salamanca, 1687, que he podido consultar en el mismo archivo, en los folios 57 y 80, se vuelven a relatar las procesiones en torno a Santa Librada.

Sobre los asuntos relativos a altares, su ubicación en los templos, desarrollo y simbología, véanse los trabajos del profesor Carrero, y como texto significativo para el caso que nos ocupa E. CARRERO SANTAMARÍA, “Retrocapillas, trasaltares y girolas. Liturgia, reliquias y enterramientos de prestigio en la arquitectura medieval", en Imágenes del poder en la Edad Media. Estudios in

\section{CONCLUSIONES}

Por todo lo expuesto, una deducción razonable basada en los documentos citados, nos conduce a pensar que las obras catedralicias pudieron iniciarse en los años treinta del siglo XII, amparadas en las donaciones reales revisadas que iban dando carta de naturaleza al obispado.

Como se ha publicado, aunque sin seguridad, tal vez, en los años veinte de la duodécima centuria, el prelado y su séquito se instalaron, provisionalmente, en la llamada zona de los huertos, en la parte baja de la población, cerca de la ribera del río Henares, aprovechando los restos de algún templo alto-medieval con sus dependencias ${ }^{82}$. Pero es necesario recordar que los componentes de este grupo, con el obispo a la cabeza, eran miembros de una Iglesia actualizada, con la Reforma romana incorporada en sus maneras de pensar y actuar, por lo que el diseño de un templo mayor que sirviese a las necesidades de vida y liturgia cotidianas era imprescindible. Bernardo de Agen fue un seguidor del arzobispo toledano Bernardo de

memoriam del profesor Fernando Galván Freile, León, 2011, tomo II, pp. 65-83.

${ }^{82}$ Una alusión documental a Santa María la Vieja, entre los huertos, en un diploma de la catedral de Sigüenza de 1322, ha llevado a los investigadores a pensar en un primer asentamiento diocesano en zona suburbana, como ocurrió en otras diócesis del Norte hispano tales como Tuy, Astorga o León, véanse E. TORMO MONZÓ, Sigüenza, Madrid, 1929, p. 29; M. C. MUÑOZ PÁRRAGA, La catedral..., pp., 29-31 e I. BANGO TORVISO, "Catedral de León. Desde la instauración de la diócesis hasta la magna obra de Manrique de Lara", en La Catedral de León en la Edad Media, León, 2004, pp. 4748. Para el caso de Astorga, el monasterio extramuros de San Dictino pudo ser residencia episcopal en el siglo IX, pero no centro catedralicio, véase E. CARRERO SANTAMARÍA, "La claustra y la canónica medieval de la Catedral de Astorga", en La Catedral de Astorga (Actas del Simposio), Zamora, 2001, pp. 98-99.

Por otra parte, Pérez Villamil ya escribió -en 1899que el templo de Santa María de los Huertos, que aún perdura, pero muy reformado, pudo tener antecedentes antiguos, "donde hemos supuesto que existió una basílica visigoda o mozárabe", pero no se inclina a pensar que allí se instaló la catedral en el siglo XII, M. PÉREZ VILLAMIL, Op. cit., p., 41. 
Sédirac y la política religiosa del momento, dictada desde la sede primada hispana y desde la corte, no era otra que poner los centros episcopales al día.

El diploma de la constitución oficial del Cabildo, fechado en el año 1144, ya trasmite la idea de una reedificación hecha con doble muro y torres. Por lo tanto, las obras del templo estaban en marcha. Además, ese colegio de canónigos regulares, a la manera del que regía San Caprasio de Agen, tuvo una formación embrionaria desde los años veinte del siglo XII, según se ha visto en la documentación, y tendría que disponer de estancias adecuadas donde desarrollar su vida en común.

Para la realización de este primer proyecto de centro episcopal, no hay duda que las estrechas relaciones con la zona aquitana fueron determinantes y es muy posible que en el diseño de la catedral se emplease un conocido y querido modelo, nos referimos a una cabecera con un ábside mayor festoneado por otros menores, más un transepto con dos absidiolas, una en cada brazo. Las dimensiones de la obra alcanzaron cotas más modestas que los ejemplos erigidos en Auch, Agen y Cahors, entre otros, pero el cuerpo del templo ya pudo proyectarse con tres naves.

Las fachadas de los pies y del transepto, de aspecto austero, entre torres, completarían lo que podemos deducir de esta primera fase constructiva, tal y como corroboraron las excavaciones de la zona meridional del templo y las señales de talla de la piedra y marcas de cantero que se han podido revisar in situ.

La donación del prelado al cabildo de 12.000 piezas de plata, en 1149 , nos puede estar indicando la necesidad de hacer frente a pagos en relación con la construcción y su acondicionamiento.

Las obras del perímetro de los muros, hasta cierta altura, se harían antes de 1156, pero las zonas superiores de los paramentos y las cubiertas del ábside mayor y del cruce- ro no estaban en ese momento terminadas, como concretó el documento citado, del segundo obispo, Pedro de Leucata.

Por otra parte, es muy posible que el claustro, al Norte, y sus dependencias fueran poco más que recintos sencillos, los cuales fueron sólo configurados en la primera mitad de la decimosegunda centuria. Un documento de 1181 habla del Capítulo Nuevo $\mathrm{y}$ una inscripción funeraria dice que el primer enterrado en la claustra es de $1192^{83}$. No cabe duda que antes tenían unas dependencias vetustas, posiblemente de materiales más pobres, destinadas a ser engrandecidas en cuanto se pudiese.

La continuación de los trabajos fue lenta y en el siglo XIII los problemas se multiplicaron, por lo que los cambios en las partes altas de los muros, respecto al diseño inicial, fueron fáciles de introducir.

\section{POSIBLES CONEXIONES CON OTROS ENCLAVES CONTEMPORÁNEOS}

En relación con el modelo que acabamos de sintetizar, osamos abrir otra línea de investigación que afectaría, por lo menos, a otros tres templos catedralicios. Nos referimos a las obras románicas realizadas en las sedes de Osma, Palencia y Segovia, campañas que desgraciadamente desconocemos en la actualidad.

No obstante, los lazos de parentesco de algunos de los prelados que rigieron estos obispados, su procedencia y vinculación con las comunidades aquitanas que hemos mencionado, unidas a las necesidades de construcción o puesta al día de sus templos mayores, nos lleva a pensar en unas campañas edilicias que pudieran tener ciertas similitudes ${ }^{84}$.

\footnotetext{
${ }^{83}$ M. C. MUÑOZ PÁRRAGA, La catedral..., p., 97.

${ }^{84}$ La directa relación de Bernardo de Sigüenza y Pedro de Segovia fue una realidad que se puede constatar al revisar la documentación de la catedral segoviana. La presencia de Bernardo de Agen es constante en las confirmaciones de los diplomas conservados, entre 1122 y 1147, en los que, mayoritariamente, los reyes, Alfonso I
} 


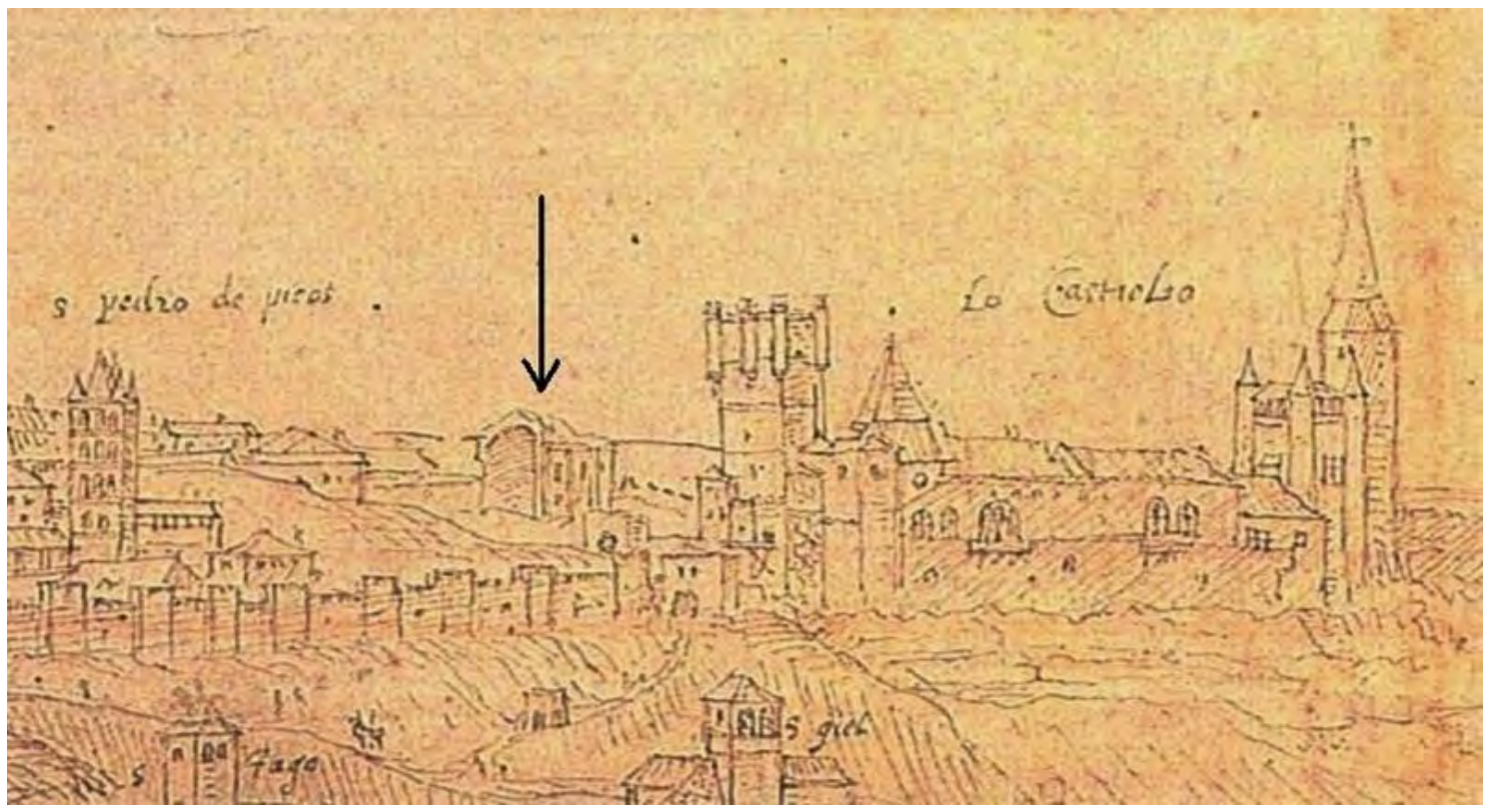

- Fig. 12. Anton_Van_den_Wyngaerde, siglo XVI (1570). Detalle de la vista de la ciudad de Segovia con los restos de la catedral románica. http://151.80.203.172/ceca/wp-content/uploads/2013/02/01.WyngaerdeC278-2.jpg

El caso de Segovia, cuya catedral de Santa María fue demolida en el siglo XVI y no quedan vestigios de interés a la vista, sólo podemos vislumbrarlo por el porte de los restos de su cabecera, recogida en un grabado de Anton-Van-den-Wyngaerde, fechado circa 1570 (Fig. 12) ${ }^{85}$. La imagen trasmite un estado avanzado de destrucción del templo mayor, pero se ve perfectamente la mole de un ábside, muy destacado en altura, con alguna absidiola menor en el lado derecho.

Parece lógico pensar que el primer obispo pleno-medieval de la sede, Pedro de

de Aragón, Urraca de León-Castilla y Alfonso VII, apuntalan la restauración de la diócesis secobiensis. Véase L. M. VILLAR GARCÍA, Op. cit., docs. 7, 9, 10, 11, 13, 18, 19, $20,21,22,25,27,28,35,36,37,38$ y 39 , en pp. $50,52,53,54$, $56,60,62,64,65,66,70,73,74,82,83,84,86$ у 87 .

${ }^{85}$ La diócesis de Segovia, tras la repoblación realizada en época del rey Alfonso VI (1066-1109), pasó a manos del arzobispo de Toledo Bernardo de Sédirac, hasta que en 1120 se consagró como obispo a Pedro de Agen (†1149), véanse B. BARTOLOMÉ HERRERO, “Espacio, Iglesia y Sociedad en las Tierras de Segovia durante los siglos XIXII", en Enciclopedia del Románico en Castilla y León. Segovia, vol. I, Aguilar de Campoo, 2007, pp. 17-47, especialmente pp. 31-32; J. A. RUIZ HERNANDO, "El románico en Segovia”, en Ibídem, pp. 49-88, especialmente pp. 59-60.
Agen (1120-1149), influiría en el diseño del templo mayor, para el cual el concejo acotó terrenos y proporcionó heredades destinadas a la construcción y al mantenimiento del clero. En 1125 ya se trasladaron al edificio las reliquias de san Frutos, santa Engracia y san Valentín y se sabe que en 1144 la catedral estaba aún en obras. Posiblemente, en 1228, pudo finalizarse esta empresa ${ }^{86}$.

En cuanto a Palencia, los investigadores han propuesto, para el periodo pleno-medieval, una primera catedral románica temprana, del siglo XI, construida sobre la cripta de San Antolín. Pero, como existe la referencia a una dedicación del templo en 1219 , se ha pensado en una posible ampliación iniciada por el obispo Raimundo II (1148-1184) y para la que se diseñaría una planta de tres naves con tres ábsides, tal vez escalonados ${ }^{87}$.

${ }^{86}$ M. BARRIO GOZALO, "La Iglesia de Segovia", en Historia de las Diócesis españolas, t. 19, Madrid, 2004, pp. 381-603, especialmente pp. 389 y 593; J. M. RODRÍGUEZ MONTAÑÉS, "Segovia”, en Enciclopedia del Románico en Castilla y León. Segovia, vol. III, Aguilar de Campoo, 2007, pp. 1347-1352, especialmente 1349-1350.

${ }^{87}$ R. MARTÍNEZ GONZÁLEZ, “La catedral visigoda y románica”, en R. J. PAYO HERNANZ y R. MAR- 
A través de las noticias documentales que hacen referencia a los trabajos en el edificio gótico, se sabe que la antigua iglesia mayor tuvo una nave central, tan ancha como la actual, con pilares cuadrangulares que daban paso a las laterales, más estrechas que las de hoy día. El cuerpo del templo ocupaba un tramo menos al oeste y tenía un claustro con capillas y enterramientos. La cabecera, de cuyo trazado nada se sabe, pudo estar cubierta con bóvedas y el cuerpo con madera $^{88}$

No descartamos que fuese Pedro II de Agen (1139-1147), antecesor del citado Raimundo, quien iniciara las obras, pues, al llegar a su sede, procedente de Segovia, en donde era arcediano, debió encontrarse con un pequeño templo que, sólo de forma embrionaria, reuniría las condiciones necesarias para los nuevos usos litúrgicos ${ }^{89}$. Además, las alusiones documentales, en estos años, a una "claustra vieja", donde estaban ubicados los sepulcros de los prelados anteriores, Raimundo (†1108) y Pedro I (†1139), podrían ayudar a pensar en obras nuevas que se alargaron hasta la centuria siguiente ${ }^{90}$. Por

TÍNEZ, La catedral de Palencia. Catorce siglos de Historia y Arte, Burgos, 2011, pp. 160-196. La documentación medieval más antigua para este enclave se puede revisar en T. ABAJO MARTÍN, Documentación de la catedral de Palencia (1035-1247), Salamanca, 1986.

${ }^{88}$ R. MARTÍNEZ GONZÁLEZ, Op. cit., pp. 186-191.

${ }^{89}$ Pedro II aparece en la documentación segoviana, en primer lugar, como archidiaconus et nepos del obispo Pedro de Agen y, posteriormente, como obispo de Palencia. Ambos tienen que firmar una concordia, que les preparó Alfonso VII en 1144, relativa a la jurisdicción de Peñafiel y Portillo, véase, L. M. VILLAR GARCÍA, $O p$. cit., docs. 17, 25, 32, 33 y 35, pp. 59, 70,79, 80 y 82 . Esta proximidad podría explicar, tal vez, la similitud de sus proyectos constructivos.

No obstante, tampoco podemos olvidar que entre los años 1109 y 1139 rigió la diócesis palentina Pedro I, que había llegado también de Agen, quien, ante la situación de su templo mayor, pudo ya querer iniciar un nuevo proyecto que continuarían sus sucesores.

${ }^{90}$ C. REGLERO DE LA FUENTE, “La Iglesia de Palencia" en Historia de las Diócesis españolas, t. 19, Madrid, 2004, pp. 5-234, especialmente, p. 222 y S. ANDRÉS ORDAX, "La catedral de Palencia y los obispos de la Alta otra parte, la noticia de 1346, relacionada con la reducción de las capellanías llevada a cabo por el obispo don Vasco, alude a los altares de la catedral románica y entre ellos se cita el de San Pedro retrochorum. ¿Sería posible pensar en una absidiola menor, tras el lugar que ocupaba el coro, para albergarlo? ${ }^{91}$.

Los enormes cambios sufridos por el edificio dificultan el conocimiento de las estructuras anteriores y sólo unas excavaciones muy completas podrían dar luz a la hipótesis aquí expuesta ${ }^{92}$.

Por último, la catedral de Osma tuvo que iniciarse tras la consagración de Pedro de Bourges en $1101^{93}$. El prelado fue otro de los clérigos franceses que promovió el arzobispo Bernardo de Toledo desde su sede primada, donde aquel pudo ocupar un puesto de arcediano $^{94}$. Pero, además, antes de llegar a la península, Pedro fue monje en el monasterio de san Orencio de Auch, lugar del que procedía también Bernardo de Sédirac ${ }^{95}$.

Edad Media (s.VI.-1247)", en Jornadas sobre la Catedral de Palencia, Palencia, 1988, pp. 13-42, especialmente p. 32.

${ }^{91}$ R. MARTÍNEZ GONZÁLEZ, Op. cit., pp. 192-193.

${ }^{92}$ Véanse S. ANDRÉS ORDAX, Op. cit., p. 32 y R. MARTÍNEZ GONZÁLEZ, "La cripta de la catedral de Palencia: nuevas respuestas a viejas cuestiones", en Monumentos singulares del románico. Nuevas lecturas sobre formas y usos, Aguilar de Campoo, 2012, pp. 9-39, con una posible planta en la página 34 . Por otra parte, no debemos olvidar que el obispo Arderico de Palencia (1184-1208) procedía de la cátedra de Sigüenza, por lo que, si las obras continuaron durante su prelatura, estas le resultarían familiares.

${ }^{93}$ Así lo denomina Jiménez de Rada en su obra, R. JIMÉNEZ DE RADA, Op. cit., pp. 252-253; véase también J. LOPERRÁEZ CORVALÁN, Op. cit. y B. BARTOLOMÉ MARTÍNEZ, "La Iglesia de Osma", en Historia de las Diócesis españolas, t. 20, Madrid, 2004, pp. 323-492, especialmente, pp. 336 y 478. 224.

${ }^{94}$ C. REGLERO, “El obispado de Osma...", pp. 183-

${ }^{95}$ T. PORTILLO CAPILLA, "La Regla de San Agustín en la catedral de Santa María de Osma", en A. IRIARTE y L. V. DÍAZ MARTÍN (coords.), Op. cit., pp. 225-244. Este primer prelado murió en Sahagún en 1109, durante los funerales por el rey Alfonso VI; es posible que antes de pasar a Toledo estuviese en el monasterio leonés, véanse B. BARTOLOMÉ MARTÍNEZ, Op. cit., 
El segundo obispo de Osma, Raimundo (1109-1125), también era gascón, de la Sauvetat des Savères, como el primado, al que sucedió en Toledo, y parece ser que prosiguió los trabajos edilicios del centro de la sede $^{96}$. En tercer lugar, el episcopado fue dirigido por Beltrán (1126-1140), también francés y procedente de un arcedianato toledano ${ }^{97}$. Durante su prelatura, el ya arzobispo Raimundo le envía una carta -fechada el 4 de abril de 1130- para apoyar la búsqueda de recursos con los que terminar las obras catedralicias y sus dependencias para los canónigos.

En el texto se especifica que el templo está dedicado a Dios y a la Virgen gloriosa, su madre, en el misterio de la Asunción. Además, se dirige a los fieles de Osma, Toledo, la metrópoli, Sigüenza y Palencia, a las que llama diócesis vecinas, para conseguir medios. También concede 40 días de indulgencia a los peregrinos, que no pudiendo viajar a otros lugares santos, visiten Osma y den una limosna equivalente a la mitad de lo que iban a gastar si se hubiesen desplazado a Roma o Compostela. Esta disposición fue aprobada por el Papa Inocencio II en 1131 y el rey Alfonso VII, en 1136, hizo donaciones para colaborar en la obra del vestuario de la

p. 478 y J. L. HERNANDO GARRIDO, “El Burgo de Osma", en Enciclopedia del Románico en Castilla y León. Soria, vol. I, Aguilar de Campoo, 2002, pp. 271-282, especialmente p. 271.

${ }^{96}$ T. PORTILLO CAPILLA, Op. cit., p. 229 y B. BARTOLOMÉ MARTÍNEZ, Op. Cit., p. 478.

${ }^{97}$ B. BARTOLOMÉ MARTÍNEZ, Op. cit., p. 478. catedral y del cabildo, lo que podría indicar sus retoques finales ${ }^{98}$.

Del primer edificio románico apenas quedan restos en algún muro del lado del evangelio y, por supuesto, en el claustro, con su sala capitular tardía y otros elementos conservados.

El resto de los materiales se reaprovecharían para las siguientes obras góticas y renacentistas de los siglos XIII y XVI; no obstante, la profesora Muñoz Párraga pensó que el ábside sur, actual capilla de la Virgen del Espino, podría ponerse en relación con la catedral de Sigüenza, pues las conexiones entre ambos centros fueron muy importantes ${ }^{99}$. Incluso, en 1774, se derriban dos absidiolas y se hace la girola, asunto que recuerda también las obras seguntinas del siglo $\mathrm{XVI}^{100}$.

El desconocimiento del subsuelo impide llegar a otras conclusiones, pero la cronología de las obras, la procedencia de sus promotores, los lazos entre ellos y las necesidades acuciantes de poseer un lugar digno para la liturgia y la vida en común de los canónigos, llevaría a los obispos a rentabilizar diseños y minimizar costes. Tal vez la uniformidad de las empresas fue mayor de lo que hasta ahora sospechábamos.

\footnotetext{
${ }^{98}$ T. PORTILLO CAPILLA, Op. cit., pp. 229-233.

${ }^{99}$ Enciclopedia del Románico en Castilla y León. Soria, vol. I, Aguilar de Campoo, 2002, pp. 272-275 y M. C. MUÑOZ PÁRRAGA, La catedral..., p., 110.

${ }^{100}$ J. M. MARTÍNEZ FRÍAS, “Catedral de El Burgo de Osma", en J. RIVERA BLANCO (coord.), Las Catedrales de Castilla y León, pp. 85-101, especialmente p.88.
} 